\title{
GNSS Assessment of Sentinel-3A ECMWF Tropospheric Delays over Inland Waters
}

\author{
Christopher Pearson ${ }^{1}$, Philip Moore ${ }^{1}$ and Stuart Edwards ${ }^{1}$ \\ 1 School of Engineering, Newcastle University, Newcastle upon Tyne, NE1 7RU, UK; \\ * Correspondence: Christopher.pearson@newcastle.ac.uk;
}

Abstract: Over land and inland waters satellite radar altimetry is being used in numerous applications including polar mass change, ice topography, river and lake heights and soil moisture. To achieve high accuracy altimetric range measurements, geophysical corrections are applied including the Zenith Total Delay (ZTD) which varies spatially, temporally and with altitude. Over oceans, the wet tropospheric component of the ZTD is usually derived from onboard radiometers. However, over land, the radiometer return is saturated and the zenith wet and dry tropospheric delays are derived separately as output of a meteorological model such as that processed by the European Centre for Medium-Range Weather Forecasts (ECMWF). Using Global Navigation Satellite System (GNSS) stations located near Sentinel-3A ground tracks and correcting for any height difference the ECMWF model is compared to the ZTD estimated from GNSS data, quantifying the likely error for inland water and land applications. We found that, globally, there is a median bias of $-3 \mathrm{~mm}$ between the ECMWF model and GNSS values with median absolute deviation (MAD) of $7.3 \mathrm{~mm}$ but with clear spatial and temporal variations. Spatially, ZTD differences are greatest within the tropics with MAD values exceeding $11 \mathrm{~mm}$, over double that of points within the Arctic Circle $(<5 \mathrm{~mm})$. Temporally, the ECMWF model differs from GNSS values more during summer months. Northern Hemisphere summer (JuneAugust) has an approximately $60 \%$ larger MAD than December-February with the summer MAD approximately $20 \%$ smaller in the Southern Hemisphere. Assessment of the tropospheric error is quantified for the largest river catchments for application to inland water heights. The close proximity of altimetric data, GNSS receiver and inland water gauges on the Amazon and Orange rivers and Lake Ontario confirms the preference for GNSS derived ZTD. Overall, the altimetric community can be reassured that the tropospheric contribution to the error budget for inland water applications is less generally than $20 \mathrm{~mm}$ at $1 \sigma$ in all major catchments.

Keywords: Sentinel-3A, altimetry, GNSS, troposphere, sensor calibration

\section{Introduction}

From the first dedicated altimetric mission in the early 1990s satellite radar altimetry has provided measurements of the sea-surface and sea-state as well as lake, river, polar ice and land heights. Irrespective of the application, altimetric heights require correction for geophysical effects including the tropospheric delay, ionospheric delay and tides. All relevant corrections are provided within the altimetric Geophysical Data Records (GDR) including the ZTD derived within a meteorological model; the accuracy of this model is critical to inland surface heights. Models to estimate the altimetric ZTD include the operational ECMWF model, the ECMWF-Interim Reanalysis (ERA) and the National Centers for Environmental Predictions (NCEP) reanalysis. The ERA-Interim reanalysis has been shown to be the best model for long term sea level monitoring (Legeais et al., 2006) as it does not exhibit step changes and drift caused by updating of the processing methodology in the operational ECMWF model. However, since 2006, the variance between ERA-Interim and operational ECMWF has been less than $5 \mathrm{~mm}^{2}$ unlike NCEP where the variance is approximately $60 \mathrm{~mm}^{2}$ (Legeais et al., 2006). One update refines the spatial resolution of the ERA-Interim model from $0.75^{\circ} \times 0.75^{\circ}$ to $0.125^{\circ} \times 0.125^{\circ}$ for the operational ECMWF model. Due to these improvements the operational ECMWF model is the most up to date, accurate and most densely populated model available to correct for the ZTD.

The ZTD is mainly caused by delay in the troposphere but also includes the effects of the tropopause and stratosphere. As such the ZTD is commonly defined as tropospheric delay. Modelling 
of the troposphere has been a focus of previous studies (Boehm et al. , 2006, Davis et al. , 1985, Hopfield, 1971, Niell, 1996, Saastamoinen, 1972). Tropospheric delay depends on temperature, pressure, humidity as well as location. The ZTD is usually split into wet and dry components; Zenith Wet Delay (ZWD) and Zenith Dry Delay (ZDD), sometimes defined as Zenith Hydrostatic Delay (ZHD). "Given the small difference between the hydrostatic and dry components of the tropospheric path delay, the term 'dry tropospheric delay' is usually used within the altimetry community to refer to the hydrostatic tropospheric path delay" (Fernandes et al., 2014). The ZWD depends on water vapour with the ZDD on pressure and elevation. The ZDD, estimated with an accuracy of about $99.8 \%$ (Wells, 1986), accounts for near $90 \%$ of the total tropospheric delay of about $2.4 \mathrm{~m}$ (Haase et al. , 2003). The ZWD is more problematic as it is spatially and temporally variable and decorrelates over distances of a few tens of kilometres. Modelling ZWD requires knowledge of meteorological conditions between the ground and the satellite.

In this study, data from the European Union's Earth observation programme Copernicus and its dedicated satellite series, Sentinel, is used. The Sentinel-3 mission aims to measure sea surface topography as well as sea and land surface temperature to support ocean forecasting systems, environmental monitoring and climate monitoring. The data from Sentinel-3A is utilised to assess the ECMWF tropospheric delays provided within the altimetric data files. Sentinel-3 is primarily an ocean monitoring mission but has applications to inland waters and land use change. Sentinel-3A was launched 16 Feb 2016 with a ground-track repeat cycle of 27 days and inclination of $98.6^{\circ}$. Data products over land can be accessed through the Copernicus Open Access Hub (https://scihub.copernicus.eu/) and are available in multiple levels depending on the application.

Sentinel-3A data files contain tropospheric delay derived by the ECMWF model CY43R3 (ECMWF, 2019). This model provides ZDD and ZWD at $1 \mathrm{~Hz}$ data rate with a spatial resolution of 0.125 ${ }^{\circ} \mathrm{x} 0.125^{\circ}$ or approximately $9 \mathrm{~km}$ (Dando, 2015). The accuracy of the ECMWF tropospheric model is pertinent to inland geophysical inferences from Sentinel-3A range measurements with systematic errors within the ECMWF aliased into the height estimates. ECMWF uses data from satellites, radiosondes, ships, buoys, weather stations etc. to provide inputs of pressure, humidity and temperature allowing a global tropospheric model to be developed. Accuracy can vary temporally and spatially due to variations in this underlying data.

Over oceans, the Sentinel-3A microwave radiometer (MWR) is more precise than models, with residual error for the dry and wet components estimated to be $7 \mathrm{~mm}$ and $14 \mathrm{~mm}$ respectively (Fletcher, 2012). Furthermore, comparisons between the ZWD values computed using the Sentinel-3A MWR and the ECMWF CY43R3 model showed a bias of between -3 and $-4 \mathrm{~mm}$ and a standard deviation of between 12 and $13 \mathrm{~mm}$ (Abdalla, 2017). The accuracy of the MWR has been previously compared to GNSS tropospheric delays in coastal regions (Fernandes and Lázaro, 2018, Lazaro, 2019). The MWR minus GNSS oceanic difference was found to a have an RMS of $22 \mathrm{~mm}$ at distances over $30 \mathrm{~km}$ from the coast but results were inferior closer than $30 \mathrm{~km}$ due to MWR contamination from land (Vieira et al. , 2018).

Previous regional studies have assessed the accuracy of weather models by comparison to GNSS derived tropospheric delays. (Chen et al. , 2012) used 49 GPS stations in Asia to conclude that the ECMWF model values had a bias of $-10 \mathrm{~mm}$ and an RMS of $27 \mathrm{~mm}$ compared to GPS derived values. A similar study (Chen et al. , 2011) using 28 GPS stations located around China revealed a bias of -10.5 $\mathrm{mm}$ and a standard deviation of $24.3 \mathrm{~mm}$ between the ECMWF and GPS ZTDs. Finally, studies (Dousa et al., 2017; Pacione et al., 2017) of GNSS stations over Europe concluded there was a bias of $-1.8 \mathrm{~mm}$ and a standard deviation of $8 \mathrm{~mm}$ between ECMWF and GNSS. These studies provided a level of confidence of the ECMWF ZTD over particular regions but were unable to discern any spatial variability in its accuracy or assess the temporal accuracy of the ECMWF model throughout the year. Global comparisons of GPS and NCEP/ERA integrated water vapour or precipitable water (PW) include Vey et al. (2010) and Parracho et al. (2018) using a global distribution of 141 and 104 GPS stations respectively. Vey et al. (2010) showed that NCEP and GPS agree well over North America and Europe but underestimated PW by $40 \%$ in the tropics with large seasonal differences in the southern 
hemisphere. Parracho et al. (2018) revealed that ERA exhibited a moist bias in the extra-tropics and a dry bias in the tropics. Our motivation is to both extend these studies and investigate the contribution of ECMWF modelling deficiencies of the ZTD over inland waters at the local and catchment scale for users of satellite altimetry.

This study uses GNSS observations to assess the global accuracy of the ECMWF model considering geographical location and time of year. Using the median and median absolute deviation (MAD) a number of subsets are chosen to investigate spatial and temporal factors that affect the quality of the tropospheric model. These statistics allow a comparison of different datasets while limiting the effect that large outliers have on the results when compared to statistics such as mean and standard deviation.

Applications of altimetric inland water heights include assimilation into hydrological models, river discharge and lake/reservoir volume change. Apart from geophysical corrections, the accuracy of the heights is related to the size of the water body. In particular, retracking of the altimetric waveform is necessary for all but the largest water bodies as well as considerations of off-nadir returns from water reflectors and contamination of the waveform by land. Validation of altimetric water heights generally utilise in situ data from a gauge. Such comparisons introduce further sources of error from the gauge itself. The distance between the gauge and the water crossing can be a primary source of error, particularly for rivers. It is noted that, for large lakes, the water surface is essentially a level surface such that multiple heights can be averaged to reduce non-systematic errors. For narrow rivers the satellite crossing may yield just a few points. Even for wide rivers, such as the Amazon, change in the river morphology between gauge and altimetric heights may result in different hydrological regimes. Crétaux et al. (2016) summarised comparisons of multi-satellite altimetric lake heights against gauge time series over a couple of decades. Using sources such as (Ricko et al. , 2012) they produced a table of RMS between the altimetric and gauge data that ranged from $30 \mathrm{~mm}$ over Lake Issykkul, $60 \mathrm{~mm}$ for Lakes Ontario and Superior, to tens of $\mathrm{cm}$ to $1 \mathrm{~m}$ over narrow lakes/reservoirs. Similarly, Birkett and Beckley (2010) indicate RMS of 30-50 mm for large lakes and reservoirs, 100-200 mm for smaller or more sheltered lakes and 200-500 mm for river channels. Later studies confirm these accuracies with (Song et al. , 2015) reporting $180 \mathrm{~mm}$ RMSE over Tibetan lakes. Such results are also satellite dependent with the Ka-band SARAL Altika mission, with its smaller footprint and insensitivity to water vapour, outperforming Ku-band altimeters such as on ERS, ENVISAT, Topex-Poseidon and Jason. For example, using 15 lakes in the Andean system, (Arsen et al. , 2015) showed a $100 \mathrm{~mm}$ RMS for Altika but $1 \mathrm{~m}$ for ENVISAT. Both Cryosat-2 and Sentinel-3A are Ku-band SAR altimeters with enhanced performance relative to the conventional single-pulse altimeters (Göttl et al. , 2016, Moore et al. , 2018, Mostafavi et al. , 2018). Moore et al. (2018) showed that, near Obidos on the Amazon, Cryosat-2 yielded an RMSE of $349 \mathrm{~mm}$ compared with $263 \mathrm{~mm}$ for Altika. Similarly, (Mostafavi, Sh, 2018) quoted 520(580) $\mathrm{mm}$ for ENVISAT and 560(370) mm for Altika at Obidos (Jatuarana) on the Amazon and 580(820) $\mathrm{mm}$ against 550 (560) $\mathrm{mm}$ for ENVISAT and SARAL at Budapest (Baja) on the Danube. For smaller rivers such as the Po, (Tourian et al. , 2016) noted RMSE of 0.7-1.2 m whilst (Birkinshaw et al. , 2010) gave RMSE of 0.41-1.99 $\mathrm{m}$ over the Mekong. The potential of inland water altimetry as virtual river stage heights is evidenced in numerous publications including Zakharova et al. (2020) for discharge estimation, Schneider et al. (2017) for calibration of a hydrological model and Paiva et al. (2013), Breda et al. (2019) and Michailovsky et al. (2013) for data assimilation into hydrological models. Biancamaria et al. (2016) present an overview of applications of the forthcoming SWOT mission to inland hydrology.

Three inland water locations with near co-located data from Sentinel-3A, GNSS and an in-situ gauge are presented to assess whether GNSS tropospheric corrections can have a positive impact. Finally, the accuracy of the ECMWF model within the 37 largest river basins will be assessed to provide insight into the magnitude of ZTD error when using altimetry for inland water studies.

\section{Methodology}

In this section ECMWF tropospheric corrections provided in the Sentinel-3A data are compared to ZTD values computed from static GNSS stations worldwide. Although ZTD changes with location and time, the magnitude of the change is assumed negligible over a few $\mathrm{km}$ and over a few minutes. ZTD 
also changes with vertical height with corrections discussed in section 2.3. Consequently, near concurrent tropospheric estimates can be compared at GNSS stations located close to the Sentinel-3A ground point.

\subsection{Sentinel-3A Data}

One year of Level 2 (SR_2_LAN) Sentinel-3A data spanning 2017 was processed. Despite Sentinel$3 \mathrm{~A}$ recording observations at $20 \mathrm{~Hz}$, some parameters, including the wet and dry tropospheric delays, are recorded at $1 \mathrm{~Hz}$ equating to a spatial resolution of approximately $9 \mathrm{~km}$ (ECMWF, 2016). Within Sentinel-3A data, tropospheric model values are presented for the dry and wet delay separately. Model values are presented at zero ground altitude where the elevation is that of the reference ellipsoid and at sub-satellite ground altitude where the elevation is taken from an orography model. The modelled value at the ground points are used to compare to GNSS derived values as both measure the total tropospheric delay essentially contained within the lower tens of kilometres of the atmosphere.

Over land ECMWF $1 \mathrm{~Hz}$ tropospheric corrections provide $\approx 1600$ corrections per pass and consequently $\approx 610,000$ corrections per 27 day cycle. Each correction corresponds to a point on the Earth's surface with given latitude and longitude as well as the Coordinated Universal Time (UTC) of the observation facilitating a search for GNSS stations operating at the same time in near proximity of the ground point.

\subsection{GNSS Data}

The Nevada Geodetic Laboratory (NGL) processes data from a global network of $~ 17000$ permanent GNSS stations (Blewitt, 2018) from which 2.7 million Sentinel-3A ground points were found within $50 \mathrm{~km}$ of an operating GNSS station in 2017 (Figure 1a). Of these ground points 0.98 million were within $30 \mathrm{~km}$ (Figure 1b) and 0.11 million within $10 \mathrm{~km}$ (Figure 1c). North America, Europe and Japan are heavily populated with GNSS stations for geophysical inferences (e.g. tectonics) and consequently make up the majority of the observations. In contrast, Asia and Africa are poorly covered.

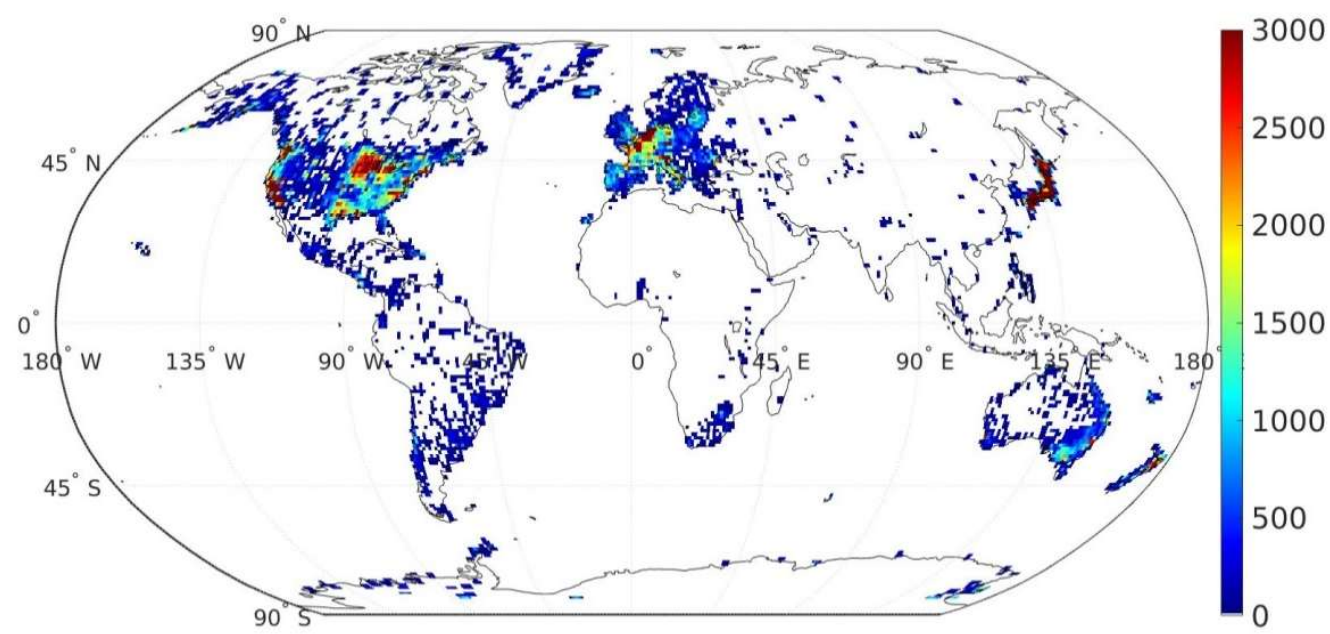



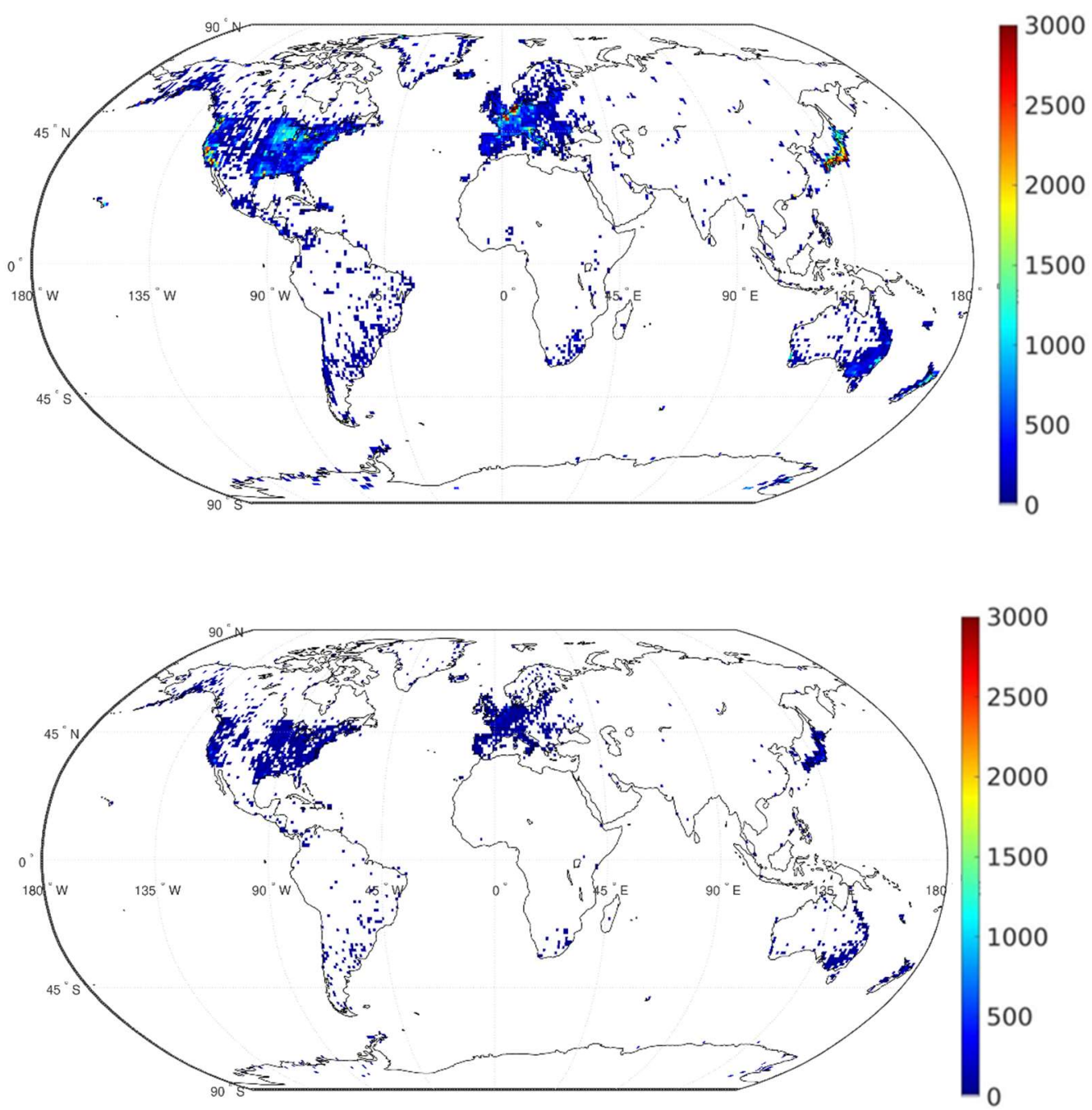

Fig. $1.1^{\circ} \times 1^{\circ}$ grid of number of comparisons between GNSS and ECMWF tropospheric delay in 2017 (capped at 3000) with maximum distances between GNSS receiver and Sentinel-3A sub-satellite ground point of $50 \mathrm{~km}$ (upper plot), $30 \mathrm{~km}$ (middle) and $10 \mathrm{~km}$ (lower).

GNSS data are processed at NGL using the Precise Point Positioning (PPP) software GIPSY-OASIS. The PPP processing strategy adopted by NGL includes products such as Jet Propulsion Lab (JPL) final orbit and clock parameters and the Vienna Mapping Function (VMF1) a priori troposphere parameters. Using the ionosphere-free LC and PC observables the zenith troposphere delay is computed every five minutes using an elevation cutoff angle of $7^{\circ}$ and ZTD gradient as random walk. These NGL ZTD values have previous been used to study tropospheric variations (Graffigna, 2019) and model accuracy (Murray, 2019). Results and full descriptions of processing parameters are freely available via the NGL website (http://geodesy.unr.edu/index.php) with files corresponding to a particular site and day of year. GNSS tropospheric estimation cannot distinguish between the dry and wet tropospheric delays and hence a total tropospheric delay every five minutes is provided alongside a standard deviation for the tropospheric estimate. Consequently, only the ZTD from the ECMWF model were used in the comparison rather than the ZWD and ZDD separately.

Alongside each tropospheric model value, values for the latitude, longitude, time and ellipsoidal height of the sub-satellite point were required to facilitate comparison. The ellipsoidal height, $H$, is not provided within the Sentinel-3A observations but can be computed to sufficient accuracy from 


$$
H=A-(R+I+Z D D+Z W D+E)
$$

where $A$ is the satellite altitude, $R$ the altimetric range, $I$ the ionospheric correction and $E$ the instrument correction for external factors such as tides. $A, R$ and $E$ are provided at $20 \mathrm{~Hz}$; in contrast to the $1 \mathrm{~Hz}$ atmospheric corrections. Consequently, the $20 \mathrm{~Hz}$ observation closest to the integral $1 \mathrm{~Hz}$ time was used to match the integer number of seconds of the atmospheric correction time stamp. Latitude, longitude and time were used to find corresponding GNSS stations within the NGL database.

\subsection{Orography and height}

Accurate information about the orography of the land surface measured by the altimetry observations is crucial to obtaining an accurate ECMWF tropospheric model value. The orography is used to compute the tropospheric delay experienced at the measurement height rather than the tropospheric delay at sea level. The orography model used by the Integrated Forecasting System (IFS) within ECMWF is a combination of data sets for different areas. The SRTM30 model (Farr and Kobrick, 2000) provides heights at a horizontal resolution of $30 \mathrm{~m}$ with a vertical accuracy of $<9 \mathrm{~m}$ (Rodriguez, 2005) for areas between $60^{\circ} \mathrm{N}$ and $60^{\circ} \mathrm{S}$. This is supplemented by GLOBE data (GLOBE, 1999) for areas north of $60{ }^{\circ} \mathrm{N}$, RAMP2 (Liu et al. , 2001) for areas south of $60{ }^{\circ} \mathrm{S}$, BPRC (Bamber et al. , 2001) for Greenland and the Iceland Digital Elevation model for Iceland (ECMWF, 2016).

Limitations with spatial resolution within the orography model, whether systematic or random, will directly affect the accuracy of the tropospheric corrections provided by ECMWF. Previous studies (Fernandes et al. , 2017) have found the ECMWF orography "can depart from the mean lake level or river profile by hundreds of metres". One example of the errors with the orography is over the Caspian Sea where the mean level is $-27 \mathrm{~m}$ but the ECMWF model has a value of $0 \mathrm{~m}$. This difference between the modelled height and true height could cause an error of approximately $7 \mathrm{~mm}$ in the subsequently computed tropospheric correction. Correcting for these potential errors in the ECMWF orography is beyond the scope of this paper.

The median of the ECMWF total tropospheric values averaged over $1^{\circ} \times 1^{\circ}$ grid squares is plotted in Figure 2 showing strong correlation between ellipsoidal height and tropospheric delay. For, example, high areas such as the Rocky Mountains in western USA yield a smaller tropospheric delay than the lower lying areas of eastern USA.

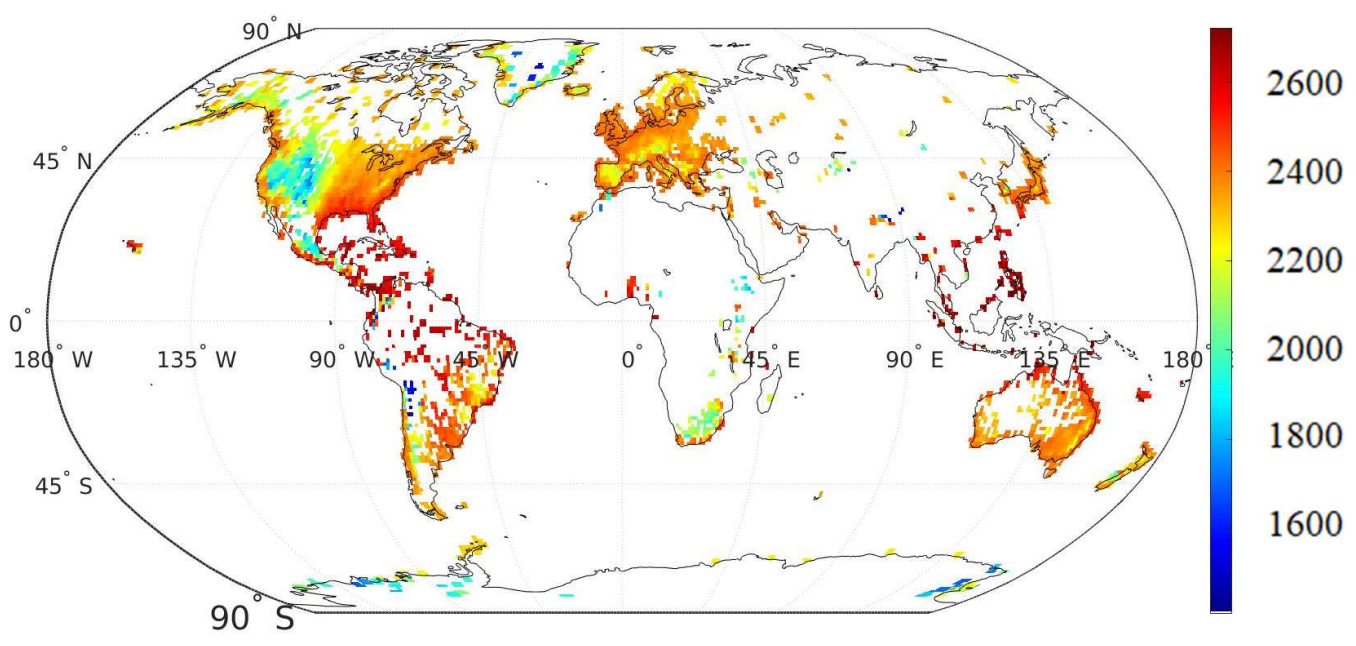

Fig. 2. $1^{\circ} \times 1^{\circ}$ grid of the median ECMWF tropospheric delay (mm)

The differential change in ZTD with ellipsodial height is addressed before comparing model and GNSS delays as Sentinel-3A sub-satellite ground points and the GNSS stations are at different heights. Changes in tropospheric delay with respect to height are different for the dry and wet troposphere. The 
dry tropospheric delay is a function of pressure, latitude and ellipsoidal height $(\mathrm{m})$ and can be reduced to sea level using (Kouba, 2008).

$$
T_{d}=\frac{0.0022768 p}{1-0.00266 \cos (2 \varphi)-0.28 \times 10^{-6} \Delta h}
$$

where $\varphi$ is latitude, $h$ the ellipsoidal height and the atmospheric pressure $p(\mathrm{hPa})$ is given by (Berg et al. , 1948).

$$
p=1013.25(1-0.0000226 h)^{5.225} \text {. }
$$

The ZWD height change can be corrected using water vapour pressure, total pressure and temperature (Teke et al, 2011; Teke et al, 2013). However, these parameters are not available for all sites in this study at the required resolution and therefore a formula where ZWD varies exponentially with height was used (Kouba, 2008).

$$
T_{w}=t_{w} e^{-\frac{\left(h_{g}-h_{e}\right)}{2000}}
$$

where $t_{w}$ is the delay at altimetric ellipsoidal height, $h_{e}$, and $h_{g}$ the GNSS receiver ellipsoidal height.

\subsection{ECMWF Zenith Total Delay}

All heights in this study are ellipsoidal relative to WGS84 reference ellipsoid. The spatial variability of the ECMWF model values corrected to zero ellipsoidal height using Eq. (2)-(4) is plotted in Figure 3. Equatorial tropospheric delays exceed that over polar regions by up to $0.35 \mathrm{~m}$ due to the differences in the ZWD. Over the warmer and more humid equatorial regions the ZWD can approach $0.35 \mathrm{~m}$, while in the desert-like conditions of the poles the ZWD is almost zero (Haase, Ge, 2003).

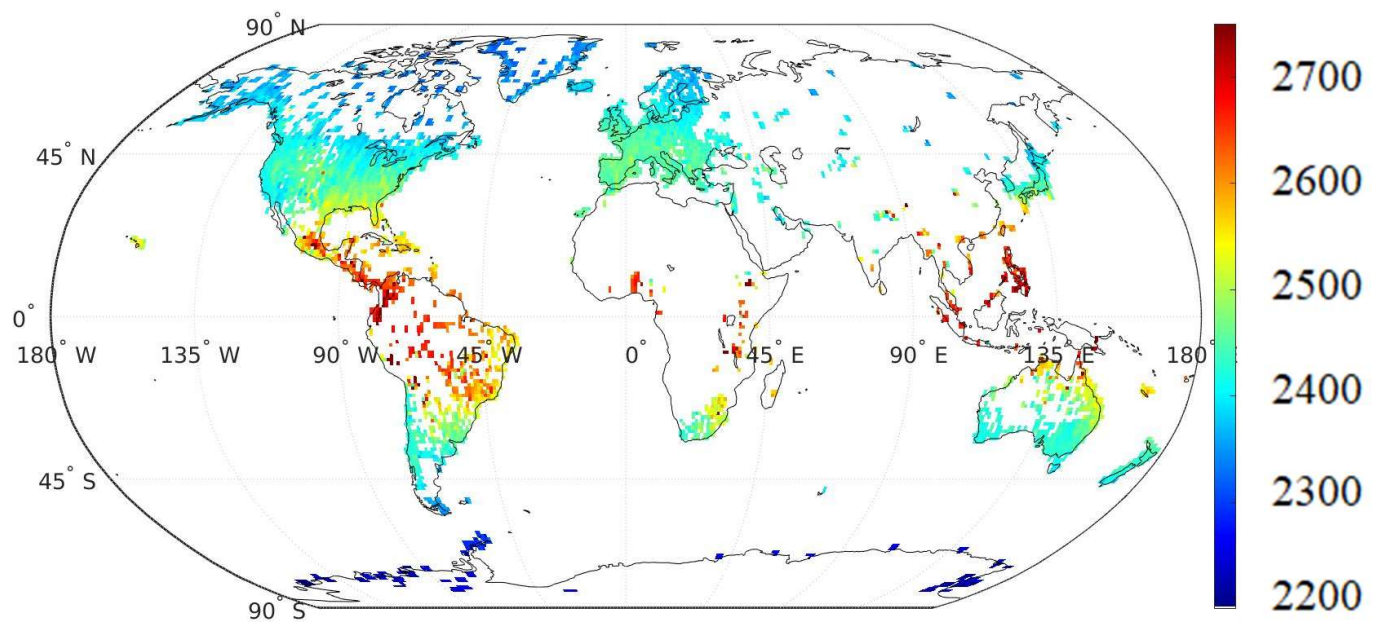

Fig. $3.1^{\circ} \times 1^{\circ}$ grid of the median ECMWF tropospheric delay corrected to zero ellipsoidal height $(\mathrm{mm})$.

Utilising the ECMWF ZTD values, the MAD of each $1{ }^{\circ} \times 1{ }^{\circ}$ bin was computed as a measure of the annual variability. The results (Figure 4) show that stations located near the Tropics of Cancer and Capricorn had the largest variation with values typically exceeding $0.05 \mathrm{~m}$, and maximum $0.12 \mathrm{~m}$. In contrast, regions near the Arctic and Antarctic circles had MAD values below $0.03 \mathrm{~m}$. Areas around the tropics show the largest seasonal change due to atmospheric water vapour content. Pan and Guo (2018) 
also found that real time recovery of the ZTD is easier in polar regions compared to mid latitude regions for similar reasons.

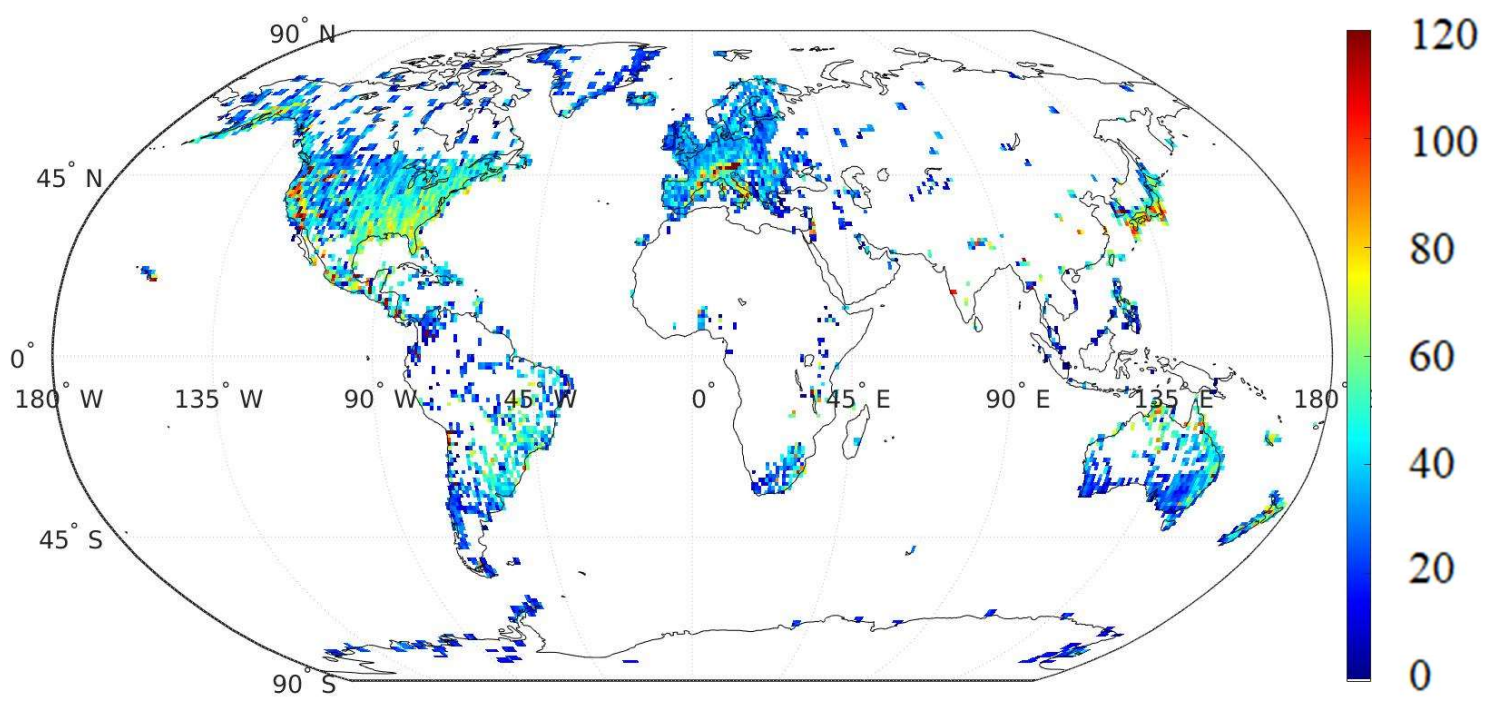

Fig. $4.1^{\circ} \times 1^{\circ}$ grid of the ECMWF tropospheric delay: mean annual MAD (mm)

\subsection{Analysis of GNSS and Altimetric Differential Heights}

Equations (2)-(4) quantify the dependence of the ZTD with height. The differential ellipsoidal height between GNSS receiver and sub-satellite ground point was used to normalise the ECMWF ZWD and ZDD to the GNSS WGS84 ellipsoidal height. ZTD differences were subsequently computed as GNSS minus ECMWF model; thus, a positive median is consistent with the GNSS ZTD exceeding the ECMWF model. ZTD differences for differential height corrections between $\pm 2000 \mathrm{~m}$ are plotted as Figure 5 showing an asymmetry between large positive and negative height differences. For a positive differential height, that is GNSS receiver above the altimetric height, the ZTD is biased towards positive values with the inference that the ECMWF ZTD has been under-corrected for the height change. The converse is true for a negative height differential. Thus, there is a deficiency in the height correction procedure at the $\mathrm{cm}$ level. 


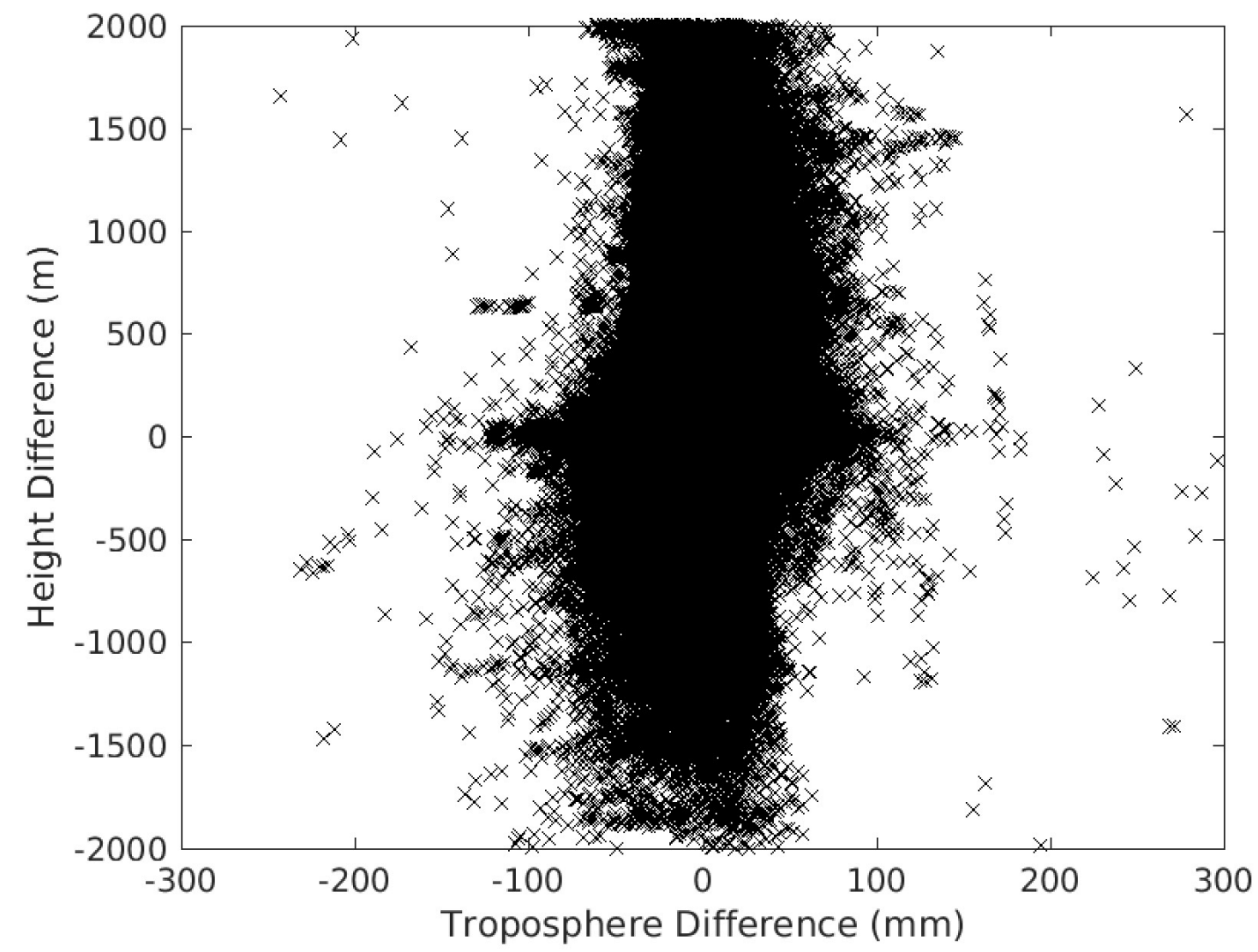

Fig 5. GNSS minus ECMWF ZTD as a function of differential height between GNSS and altimetric ground points.

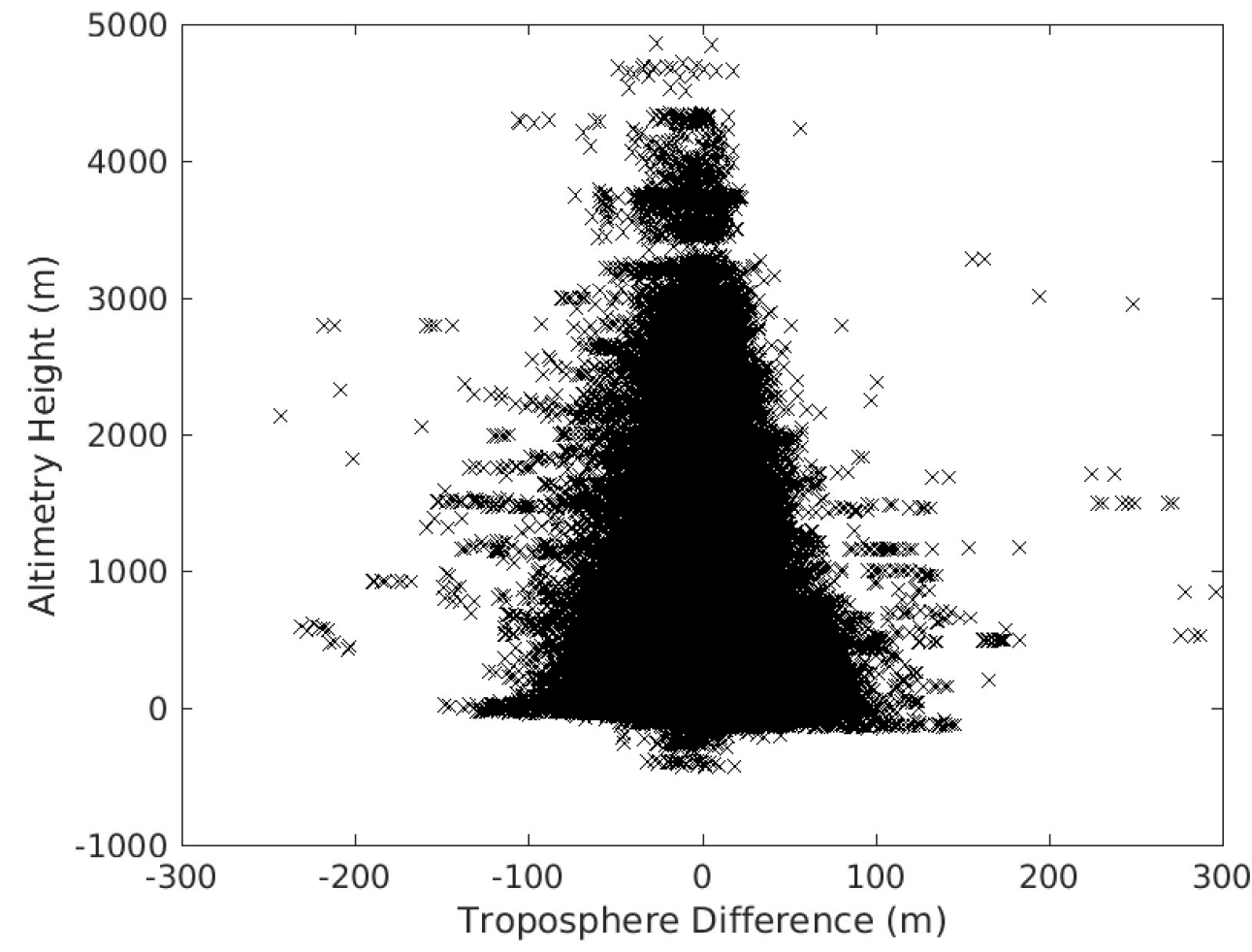

Fig. 6. GNSS minus ECMWF ZTD as a function of Sentinel-3A altimetric ellipsoidal height. 
Figure 6 shows the same asymmetry between the ZTD difference and the Sentinel-3A ellipsoidal height. For large Sentinel-3A ellipsoidal heights the altimetric point is more likely to be at a higher altitude than the GNSS receiver. The bias towards negative ZTD differences again reflects the over correction for the height change. Table 1 summarise the data of Figure 6 divided into $500 \mathrm{~m}$ height bands based on the altimetric height with 94(87) \% of all points below 1000(500) $\mathrm{m}$ in ellipsoidal height. The table shows little change in the variation for points below $3000 \mathrm{~m}$ although the bias fluctuates from $\approx-3 \mathrm{~mm}$ for heights above $500 \mathrm{~m}$. The sparsity of points at high altitude prevents detailed analysis as outliers can considerably affect the results. Sentinel-3A data are rarely used at altitudes above $2500 \mathrm{~m}$.

\begin{tabular}{|c|c|c|c|}
\hline $\begin{array}{c}\text { Ellipsoidal } \\
\text { height }(\mathrm{m})\end{array}$ & Bias $(\mathrm{mm})$ & MAD $(\mathrm{mm})$ & Count \\
\hline $4500<\mathrm{H} \leq 5000$ & -20.4 & 14.3 & 24 \\
\hline $4000<\mathrm{H} \leq 4500$ & -6.1 & 9.1 & 151 \\
\hline $3500<\mathrm{H} \leq 4000$ & -5 & 5.7 & 1349 \\
\hline $3000<\mathrm{H} \leq 3500$ & -0.8 & 2.1 & 2351 \\
\hline $2500<\mathrm{H} \leq 3000$ & -0.1 & 5.9 & 6783 \\
\hline $2000<\mathrm{H} \leq 3500$ & 0.8 & 5.8 & 15955 \\
\hline $1500<\mathrm{H} \leq 2000$ & 1.2 & 6.6 & 44206 \\
\hline $1000<\mathrm{H} \leq 1500$ & 0.3 & 6.5 & 88815 \\
\hline $500<\mathrm{H} \leq 1000$ & -2.1 & 7.4 & 201481 \\
\hline $0<\mathrm{H} \leq 500$ & -3.4 & 7.2 & 2073209 \\
\hline $\mathrm{H} \leq 0$ & -3.2 & 7.4 & 285723 \\
\hline
\end{tabular}

Table 1. 2017 GNSS minus ECMWF Sentinel-3A ZTD delays: Distribution and statistics with ellipsoidal height.

Details of the height differential between GNSS and altimetry points are given in Table 2; $82.8 \%$ of points lie within $\pm 200 \mathrm{~m}$. Over this height range equatorial ZDD decreases by $\approx 54 \mathrm{~mm}$ for a $200 \mathrm{~m}$ increase in height, or the $25-30 \mathrm{~mm}$ per $100 \mathrm{~m}$ change in height often quoted. The ZWD changes as a percentage of the wet delay. For a $200 \mathrm{~m}$ height increase the wet delay reduces in magnitude by a factor $\approx 0.9$. In areas with high ZWD (say $0.4 \mathrm{~m}$ ) this will cause a $40 \mathrm{~mm}$ change but areas with low ZWD (say $0.1 \mathrm{~m}$ ) the change is $10 \mathrm{~mm}$. Errors using Eq. (2) -(4) are expected to be considerably smaller. Table 2 shows a correlation with height change between GNSS and ECMWF values. An increase in absolute differential height correlates with an increase in the MAD value. Similarly, the median departs from $3.1 \mathrm{~mm}$ as the absolute differential height increases. However, extreme height differences account for only a few percent of the data and we can assume that the ZDD and ZWD normalisation to the GNSS height does not severely impact the results. 


\begin{tabular}{|c|c|c|c|c|c|}
\hline $\begin{array}{c}\text { lower limit } \\
(\mathrm{m})\end{array}$ & $\begin{array}{c}\text { upper limit } \\
(\mathrm{m})\end{array}$ & $\begin{array}{c}\text { median } \\
(\mathrm{mm})\end{array}$ & $\begin{array}{c}\text { MAD } \\
(\mathrm{mm})\end{array}$ & count & $\%$ \\
\hline-2000 & -1000 & -1.7 & 12.6 & 33659 & 1.24 \\
\hline-1000 & -800 & -1.6 & 10.6 & 25975 & 0.96 \\
\hline-800 & -600 & -2.6 & 9.3 & 43653 & 1.61 \\
\hline-600 & -400 & -2.2 & 8.3 & 74554 & 2.74 \\
\hline-400 & -200 & -2.2 & 7.4 & 160840 & 5.92 \\
\hline-200 & 0 & -3.2 & 6.9 & 1571288 & 57.81 \\
\hline 0 & 200 & -3.1 & 7.3 & 680586 & 25.04 \\
\hline 200 & 400 & -2.6 & 8.7 & 78577 & 2.89 \\
\hline 400 & 600 & -2.8 & 10.4 & 26748 & 0.98 \\
\hline 600 & 800 & -0.4 & 12.2 & 11033 & 0.41 \\
\hline 800 & 1000 & 3.1 & 13.5 & 5042 & 0.19 \\
\hline 1000 & 2000 & -1.6 & 16.6 & 6199 & 0.23 \\
\hline
\end{tabular}

Table 2. Statistics of 2017 GNSS minus ECMWF ZTD with respect to ellipsoidal height band

\subsection{Tropospheric Delay Spatial Decorrelation}

As stated previously, the tropospheric delay decorrelates with distance placing a limit on the maximum baseline distance between GNSS receiver and satellite ground point. This study, as in (Haase, $\mathrm{Ge}, 2003$ ), assumes $50 \mathrm{~km}$ as the maximum distance between ground points and GNSS. To verify that a lower limit is not required the global dataset was analysed with maximum baseline distance reduced from $50 \mathrm{~km}$ in steps of $10 \mathrm{~km}$ (Figure 7, Table 3). Similarity between the modelled and GNSS values increases as the separation distance decreases. However, the improvement in MAD for data within 10 $\mathrm{km}$ only yields a $10 \%$ improvement over the $50 \mathrm{~km}$ limit while $\approx 96 \%$ of the data was eliminated. This $\approx 96 \%$ reduction in the data also had a significant impact on the spatial variability of the data as can be seen in Figures 1a and 1c. Furthermore, there is negligible change in the overall bias. Therefore, it was decided to continue to use an upper limit of $50 \mathrm{~km}$, to maintain the largest amount of data and best spatial variability possible whilst not affecting the accuracy of the results. 


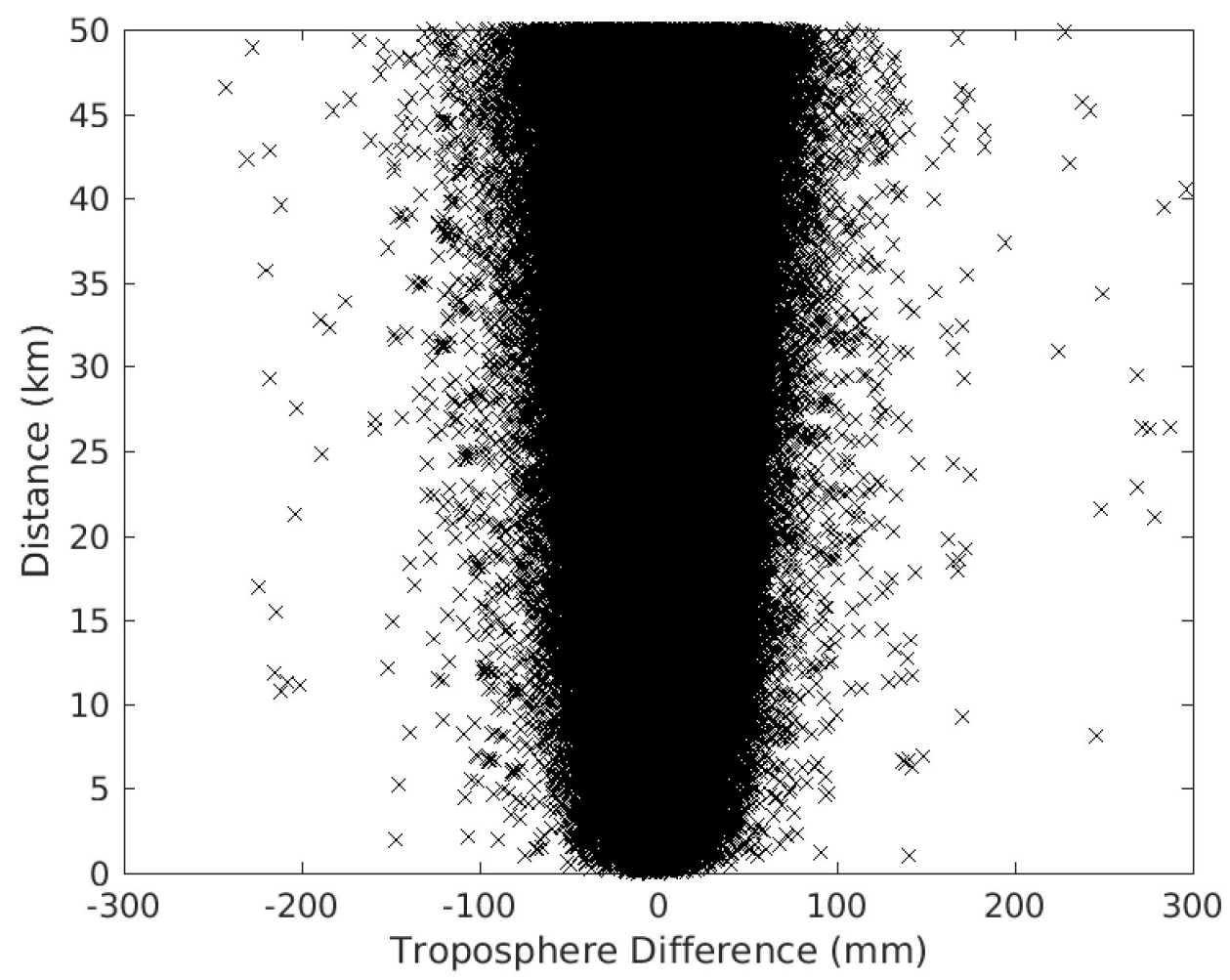

Fig. 7. GNSS minus ECMWF ZTD as a function of distance between GNSS and altimetric ground points.

\begin{tabular}{|c|c|c|c|}
\hline Maximum distance & Bias $(\mathrm{mm})$ & MAD $(\mathrm{mm})$ & Count \\
\hline$<50 \mathrm{~km}$ & -3 & 7.3 & $2,720,036$ \\
\hline$<40 \mathrm{~km}$ & -3 & 7.1 & $1,742,672$ \\
\hline$<30 \mathrm{~km}$ & -3.1 & 6.9 & 983,391 \\
\hline$<20 \mathrm{~km}$ & -3.1 & 6.7 & 439,677 \\
\hline$<10 \mathrm{~km}$ & -3.2 & 6.6 & 112,803 \\
\hline
\end{tabular}

Table 3. Statistics of GNSS minus ECMWF model ZTD with maximum horizontal distance $10-50 \mathrm{~km}$.

\section{Results}

This section presents comparisons of the GNSS ZTD to ECMWF modelled tropospheric values differentially corrected to the GNSS receiver height. Collectively the 2.7 million ZTD differences have a median bias of $-3 \mathrm{~mm}$ (Figure 8) implying that on average the tropospheric delay estimate from ECMWF is greater in magnitude than the GNSS value. The MAD of the observations is $7.3 \mathrm{~mm}$ (Figure 9). These results compared well to the previous mentioned results from European studies (Dousa, 2017; Pacione, 2017), where a $1.8 \mathrm{~mm}$ bias and standard deviation of $8 \mathrm{~mm}$ was found. 


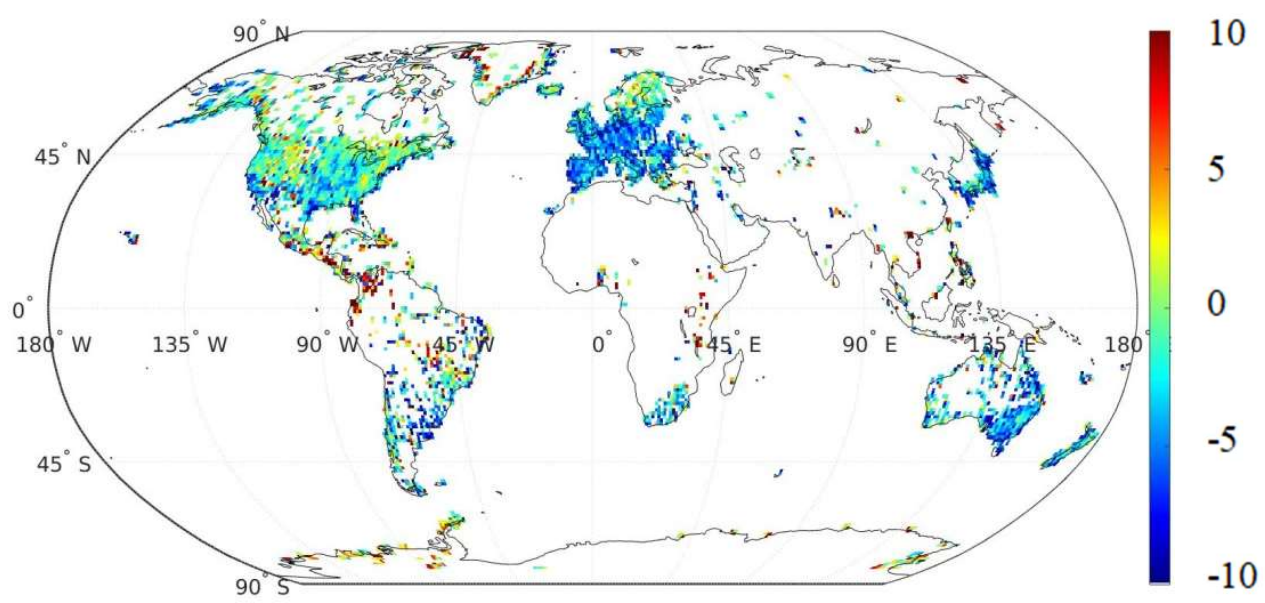

Fig. $8.1^{\circ} \times 1^{\circ}$ grid of the median difference $(\mathrm{mm})$ between GNSS and ECMWF tropospheric delay (capped at $\pm 0.01 \mathrm{~m}$ )

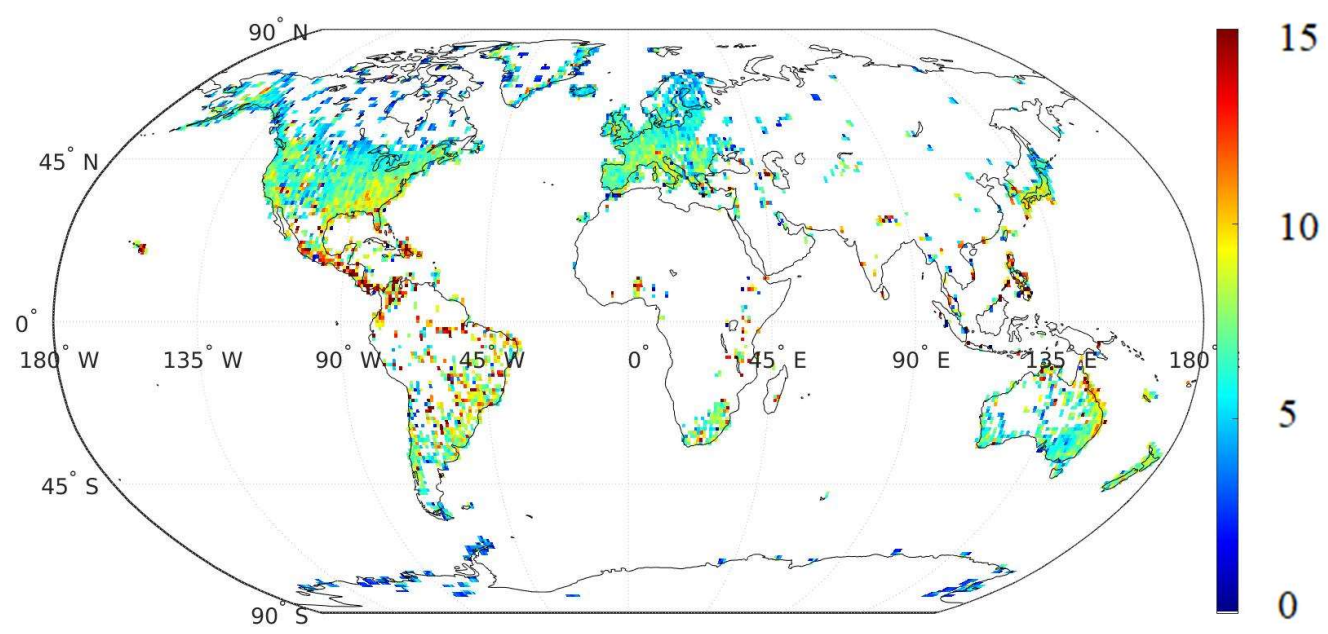

Fig. $9.1^{\circ} \times 1^{\circ}$ grid of the MAD of the difference $(\mathrm{mm})$ between GNSS and ECMWF tropospheric delay (capped at $0.015 \mathrm{~m}$ )

Sites closer to the equator tend to have larger MAD (Figure 9) although this will be examined later. Other locations with large MADs include mountainous regions such as the Himalayas and the Sierra Nevada in California. In these regions the dry tropospheric correction from the ECMWF model can be uncertain due to rapid changes in elevation. With tropospheric model values updated at $1 \mathrm{~Hz}$ the ellipsoidal height of the satellite ground track can change greatly within one second (i.e. 6-7 km) over mountainous regions. Consequently, the dependence of the dry tropospheric model to pressure and hence elevation may lead to a discrepancy with the GNSS value that cannot be resolved. This effect was mitigated to some extent by utilising the $20 \mathrm{~Hz}$ observation closest to the integer time stamp of the model to reduce the height difference between the Sentinel-3A sub-satellite point and the GNSS elevation. In non-mountainous regions large differences are usually found in remote locations such as 
Antarctica where input data used to create the ECMWF model is reduced due to fewer sensors monitoring the environment.

\subsection{Latitudinal Variation}

To investigate spatial errors within the ECMWF model ZTD differences were subdivided into $10^{\circ}$ latitudinal bands (Table 4 and Figure 10). The banding shows the MAD statistic is largest in equatorial regions, decreasing in general towards the poles. ZTD differences in the tropics, $\left(-20^{\circ}<\varphi<\right.$ $20^{\circ}$ ) have average MAD of approximately $11.1 \mathrm{~mm}$, almost $250 \%$ larger than the Arctic or Antarctic, $\left(\varphi>70^{\circ}\right.$ and $\left.\varphi<-70^{\circ}\right)$ where the average MAD is $4.7 \mathrm{~mm}$. The tropics display a number of outliers with large differences between the modelled and GNSS values, which most likely can be attributed to mountainous locations, as previously discussed. A further possibility is that the latitudinal variation shows a correspondence between high MAD values and high ZTD. However, the standard deviations of the GNSS troposphere estimates provided by NGL in Table 4 show little variation in the accuracy of estimates with changes in latitude. Therefore, spatial distribution of differences is likely due in part to deficiencies in the ECMWF modelling of the equatorial atmospheric water vapour content, in contrast to the reduced ZWD at the poles.

\begin{tabular}{|c|c|c|c|c|}
\hline Latitude & Bias $(\mathrm{mm})$ & MAD $(\mathrm{mm})$ & Count & GNSS STD $(\mathrm{mm})$ \\
\hline $80^{\circ}<\varphi \leq 90^{\circ}$ & -2.8 & 5.7 & 10318 & 1.23 \\
\hline $70^{\circ}<\varphi \leq 80^{\circ}$ & -2.6 & 4.9 & 43395 & 1.31 \\
\hline $60^{\circ}<\varphi \leq 70^{\circ}$ & -0.9 & 5.3 & 104320 & 1.23 \\
\hline $50^{\circ}<\varphi \leq 60^{\circ}$ & -4.2 & 6.5 & 350526 & 1.16 \\
\hline $40^{\circ}<\varphi \leq 50^{\circ}$ & -2.9 & 6.9 & 932088 & 1.28 \\
\hline $30^{\circ}<\varphi \leq 40^{\circ}$ & -3.5 & 8.2 & 789427 & 1.32 \\
\hline $20^{\circ}<\varphi \leq 30^{\circ}$ & -4.6 & 8.2 & 83743 & 1.30 \\
\hline $10^{\circ}<\varphi \leq 20^{\circ}$ & 1.9 & 11.5 & 35711 & 1.29 \\
\hline $0^{\circ}<\varphi \leq 10^{\circ}$ & 2.3 & 11.9 & 14027 & 1.38 \\
\hline$-10^{\circ}<\varphi \leq 0^{\circ}$ & -1.5 & 11 & 12341 & 1.34 \\
\hline$-20^{\circ}<\varphi \leq-10^{\circ}$ & -2.5 & 9.9 & 21911 & 1.37 \\
\hline$-30^{\circ}<\varphi \leq-20^{\circ}$ & -4.2 & 8.7 & 65063 & 1.39 \\
\hline$-40^{\circ}<\varphi \leq-30^{\circ}$ & -4.3 & 7.3 & 146596 & 1.40 \\
\hline$-50^{\circ}<\varphi \leq-40^{\circ}$ & -3.1 & 7.6 & 32504 & 1.32 \\
\hline$-60^{\circ}<\varphi \leq-50^{\circ}$ & -2.8 & 6.5 & 3352 & 1.29 \\
\hline$-70^{\circ}<\varphi \leq-60^{\circ}$ & 2.1 & 3.8 & 11337 & 1.19 \\
\hline$-80^{\circ}<\varphi \leq-70^{\circ}$ & 1.7 & 4.5 & 39747 & 1.32 \\
\hline$-90^{\circ}<\varphi \leq-80^{\circ}$ & 2.7 & 3.6 & 23632 & 1.42 \\
\hline
\end{tabular}

Table 4. Statistics of ECMWF minus GNSS ZTD differences and GNSS STD; $10^{\circ}$ latitudinal bands 




Fig. 10. ECMWF minus GNSS ZTD differences; $10^{\circ}$ latitudinal bands

\subsection{Seasonal Variation}

To assess seasonal variation in pressure and humidity and accuracy of the ECMWF model the dataset was divided into monthly bins. Table 5 and Figure 11 show that the GNSS and ECMWF modelled values were more consistent during the Northern Hemispheres (NH) winter (Dec. to Feb.). During the NH summer (Jun. to Aug.) the variability (MAD average $9.2 \mathrm{~mm}$ ) noticeably exceeded that during the NH winter (average MAD $6.2 \mathrm{~mm}$ ). Further, during the $\mathrm{NH}$ autumn and winter (Sep. to Feb.) the bias increased in magnitude, from approximately $-2.5 \mathrm{~mm}$ to $-3.5 \mathrm{~mm}$. The GNSS tropospheric estimate standard deviations in Table 5 show throughout the year there is maximum variation of 0.03 $\mathrm{mm}$. Consequently, any change in the variation between GNSS and ECMWF is likely caused by deficiencies in the ECMWF model.

Due to the location of the global network of GNSS stations (Fig. 1) the results are dominated by the NH. To avoid geographical bias data was further separated into $\mathrm{NH}$ and Southern Hemisphere (SH). Any global seasonal signature due, for example, to higher pressure during the summer months should be reversed over the hemispheres.

The results (Table 6 and Figure 12) show that during the NH and SH respective summer months the variability increased compared to the respective winter months. In the NH summer, June to August, the average MAD of $9.7 \mathrm{~mm}$ exceeds $5.9 \mathrm{~mm}$ during the winter, a reduction of approximately $40 \%$. Similarly, in the SH summer months, December to February, the average MAD of $8.1 \mathrm{~mm}$ is larger than $6.8 \mathrm{~mm}$ seen in the winter. 


\begin{tabular}{|c|c|c|c|c|}
\hline & Bias $(\mathrm{mm})$ & MAD $(\mathrm{mm})$ & Count & GNSS STD $(\mathrm{mm})$ \\
\hline January & -3.6 & 6.3 & 226658 & 1.29 \\
\hline February & -3 & 6.3 & 205729 & 1.27 \\
\hline March & -3.3 & 6.6 & 238932 & 1.30 \\
\hline April & -2.6 & 6.4 & 217992 & 1.28 \\
\hline May & -2.5 & 7.3 & 242802 & 1.29 \\
\hline June & -2.2 & 8.7 & 218720 & 1.29 \\
\hline July & -2.6 & 9.7 & 226542 & 1.29 \\
\hline August & -2.9 & 9.3 & 231124 & 1.29 \\
\hline September & -3 & 8.2 & 216021 & 1.30 \\
\hline October & -3.8 & 7.7 & 226988 & 1.30 \\
\hline November & -3.3 & 6.6 & 230427 & 1.27 \\
\hline December & -3.1 & 6.1 & 238101 & 1.30 \\
\hline
\end{tabular}

Table 5. GNSS minus ECMWF ZTD and GNSS STD: Monthly statistics for 2017

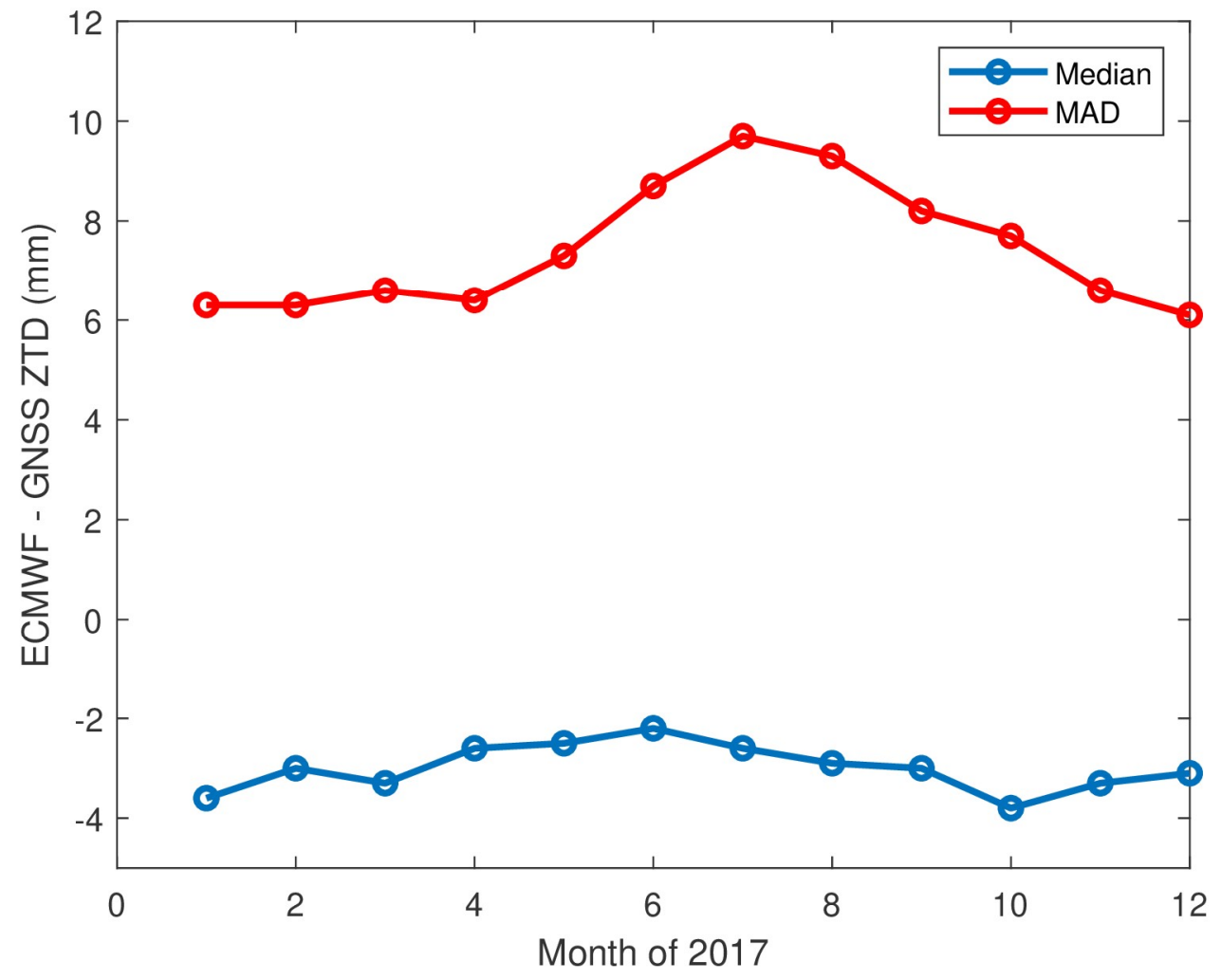

Fig. 11. GNSS minus ECMWF ZTD: Monthly median and variability 2017. 


\begin{tabular}{|c|c|c|c|c|c|c|}
\hline & \multicolumn{3}{|c|}{ Northern Hemisphere } & \multicolumn{3}{c|}{ Southern Hemisphere } \\
\hline & $\begin{array}{c}\text { Bias } \\
(\mathrm{mm})\end{array}$ & $\begin{array}{c}\text { MAD } \\
(\mathrm{mm})\end{array}$ & Count & $\begin{array}{c}\text { Bias } \\
(\mathrm{mm})\end{array}$ & $\begin{array}{c}\text { MAD } \\
(\mathrm{mm})\end{array}$ & Count \\
\hline January & -3.9 & 5.9 & 196436 & -0.3 & 9 & 30222 \\
\hline February & -3.4 & 6 & 178067 & 0.1 & 8 & 27662 \\
\hline March & -3.6 & 6.4 & 206823 & -1.1 & 8.2 & 32109 \\
\hline April & -2.7 & 6.2 & 189940 & -1.7 & 7.1 & 28052 \\
\hline May & -2.5 & 7.3 & 211147 & -2.6 & 7 & 31655 \\
\hline June & -1.9 & 9.1 & 189597 & -3.2 & 6.7 & 29123 \\
\hline July & -2.4 & 10.3 & 197126 & -3.3 & 6.9 & 29416 \\
\hline August & -2.6 & 9.8 & 201817 & -4 & 6.8 & 29307 \\
\hline September & -2.9 & 8.3 & 188090 & -3.4 & 7.5 & 27931 \\
\hline October & -4.1 & 7.7 & 198021 & -1.6 & 7.3 & 28967 \\
\hline November & -3.5 & 6.5 & 200005 & -1.2 & 7.1 & 30422 \\
\hline December & -3.3 & 5.9 & 206484 & -1 & 7.4 & 31617 \\
\hline
\end{tabular}

Table 6. GNSS minus ECMWF ZTD: SH and NH monthly statistics for 2017.

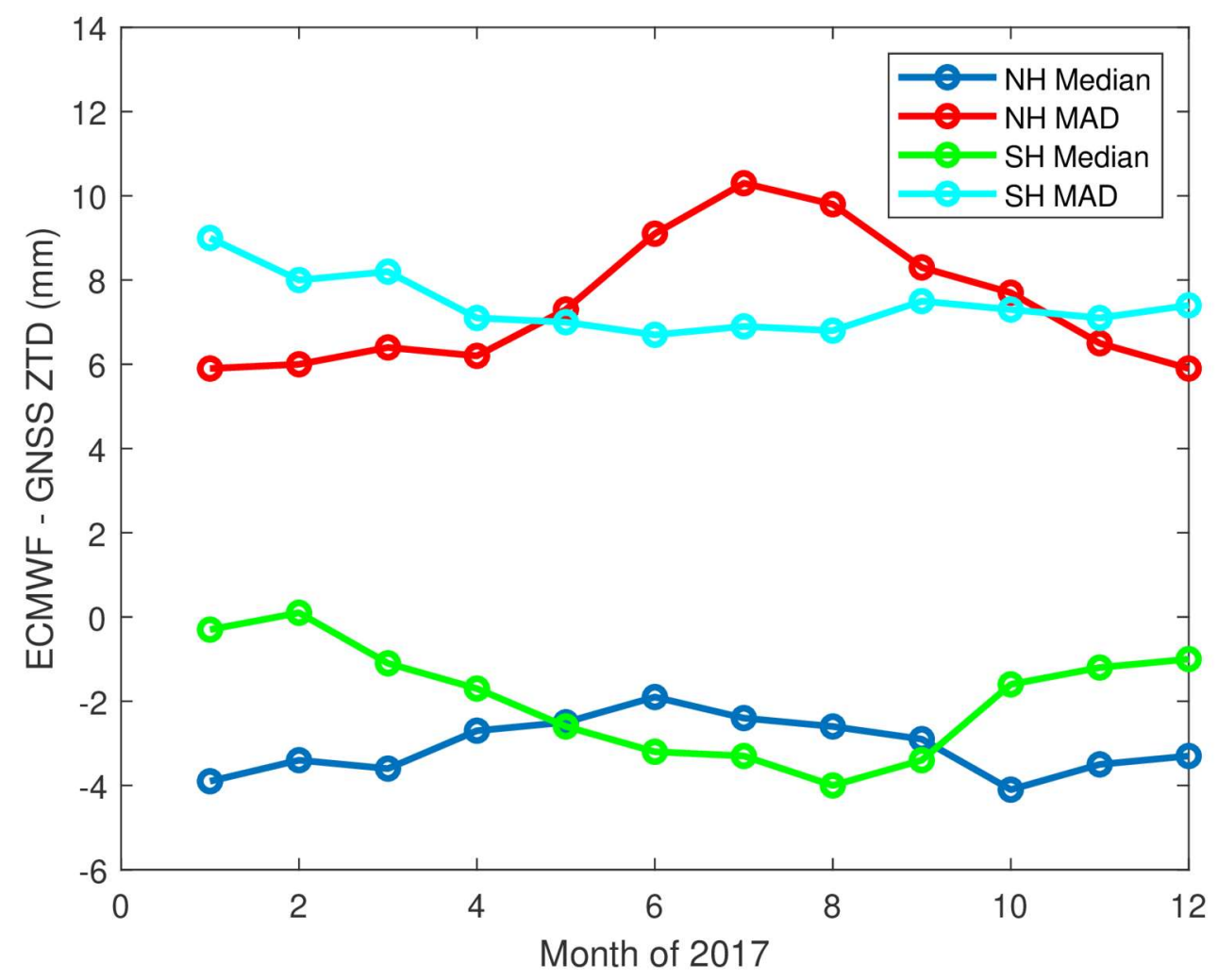

Fig. 12. GNSS minus ECMWF ZTD: SH and NH monthly median and variability for 2017. 


\subsection{Hydrological Validation}

Although the error due to ZTD mis-modelling may be only a small percentage of the overall error budget the significance of the ZTD error is dependent on spatial and temporal factors including the size of the water target. To ascertain the value of the GNSS ZTD as a replacement for ECMWF derived tropospheric corrections three validation studies were undertaken. Locations were selected based on data availability within a radius of approximately $50 \mathrm{~km}$. In addition to co-location of altimetry and GNSS, the sites further required a water level gauge. Sentinel-3A water heights for rivers and lakes were taken from the Copernicus Global Land Service (https://land.copernicus.eu/global/), ECMWF modelled tropospheric delay from Sentinel-3A Level-2 data downloaded from the Copernicus Open Access Hub with GNSS computed tropospheric estimates, as previously, downloaded from NGL. The river or lake gauge time series are compared to altimetric inland water heights with allowance for different vertical reference frames and ZTD. Validation sites encompassed the high, intermediate and low altimetric consistency with gauge data.

\subsubsection{Tabatinga, Amazon}

Sentinel-3A pass number 288 crosses the upper Amazon basin in the proximity of two GNSS receivers, AMTA and LETA (Fig. 13), located $\approx 45 \mathrm{~km}$ from the river crossing. A gauge is located $\approx 25 \mathrm{~km}$ from the GNSS receivers and $\approx 60 \mathrm{~km}$ away from the Sentinel-3A pass as measured along the course of the river. In total 25 Sentinel-3A repeat passes were used between July 2016 and October 2018. Data for the gauge was supplied by SO Hybam (www.ore-hybam.org/). ECMWF corrected river heights yielded RMSE of $404 \mathrm{~mm}$ with gauge data (Fig. 14). The difference has a significant component due to the large distance between gauge and Sentinel-3A pass. Utilising GNSS tropospheric corrections lead to no change in the RMSE of $404 \mathrm{~mm}$.

\section{Sentinel-3A Pass - GNSS Location Gauge Location}

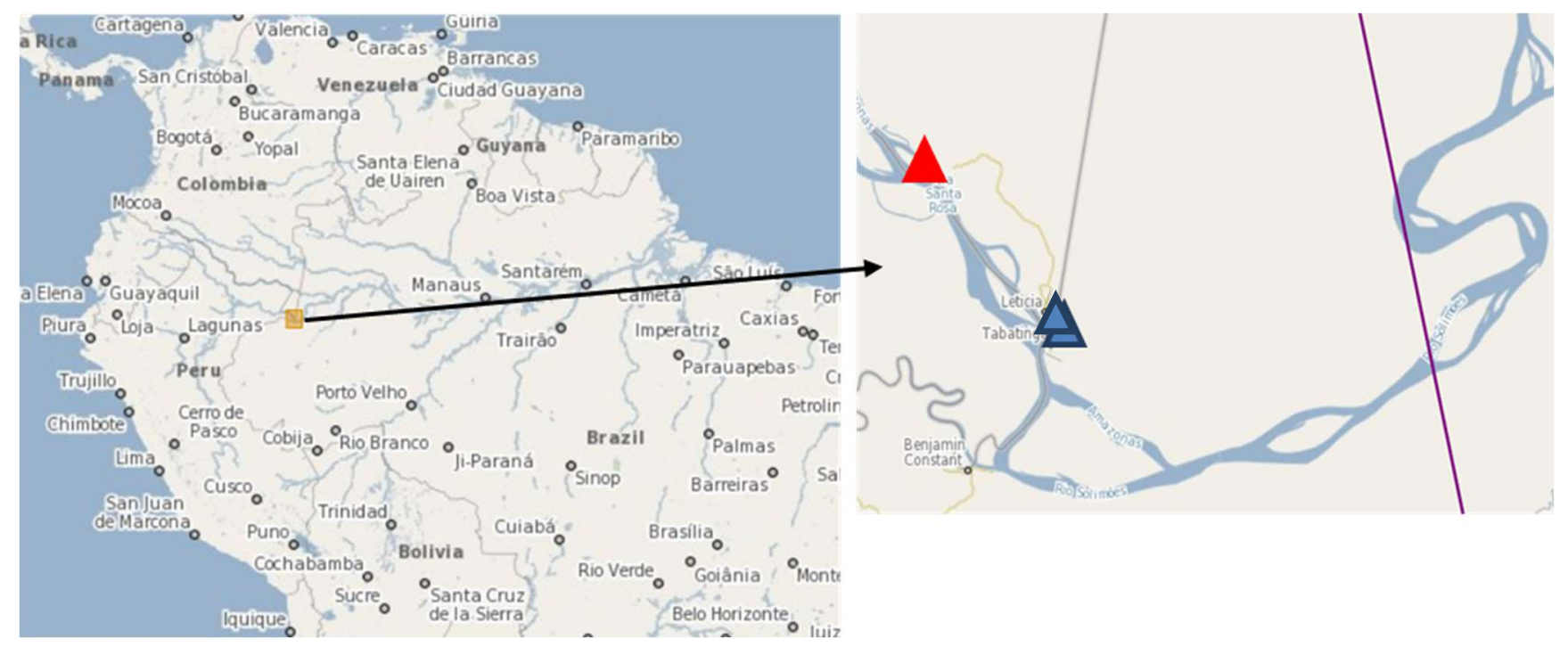

Fig. 13. Tabatinga; Sentinel-3A pass, GNSS receivers and gauge 


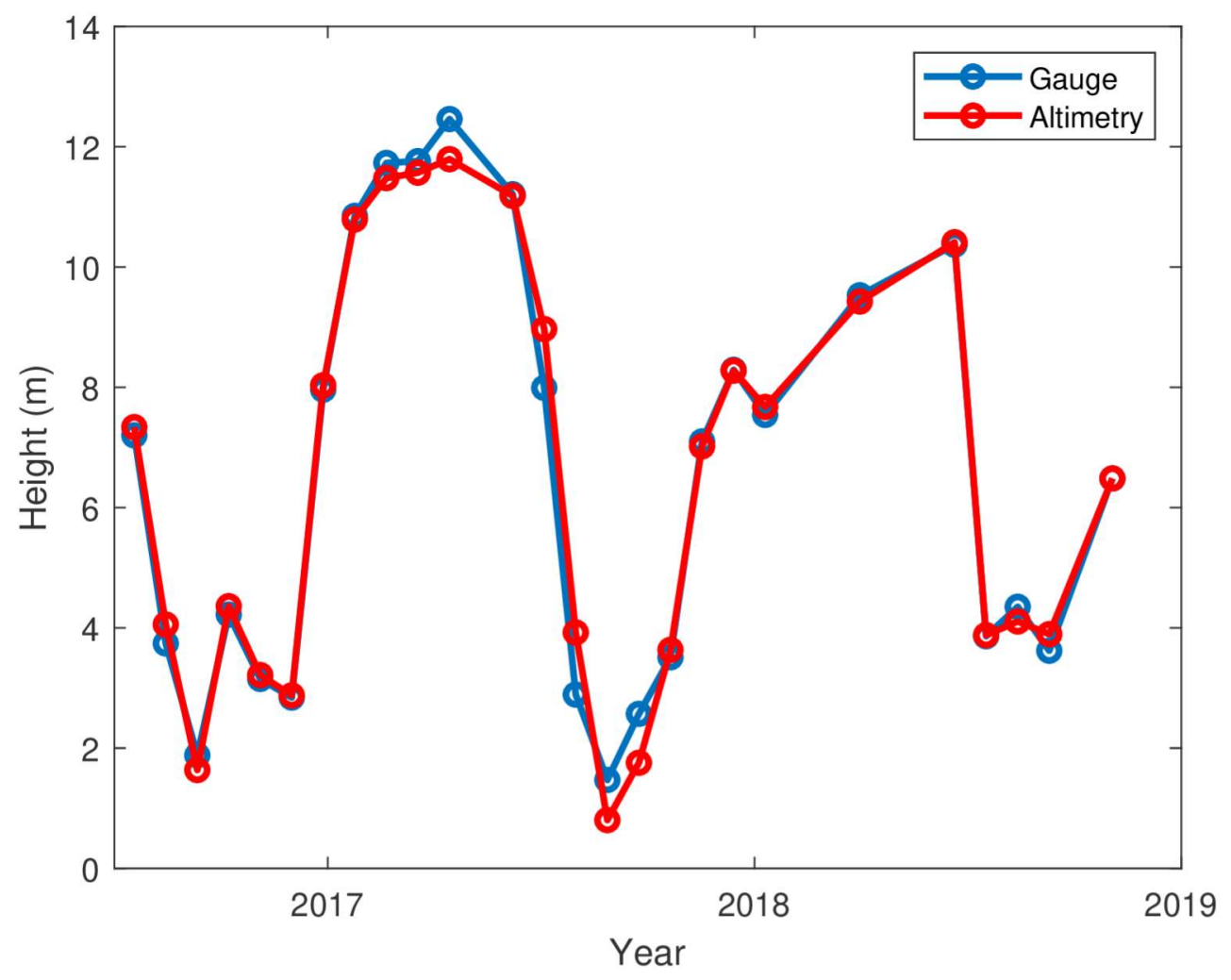

Fig. 14. Tabatinga Gauge and ECMWF corrected Altimetric river height comparison

\subsubsection{Prieska, Orange River, South Africa}

Sentinel-3A pass number 142 crosses the Orange River approximately $30 \mathrm{~km}$ from the GNSS receiver PSKA with a river gauge located $\approx 1 \mathrm{~km}$ from PSKA and $\approx 30 \mathrm{~km}$ from the Sentinel-3A river crossing (Fig. 15). This data provided 29 repeat pass heights between April 2016 and October 2018. Data for the gauge was supplied by Bundesanstalt für Gewässerkunde (BfG).

At Prieska ECMWF tropospheric corrected heights yielded RMSE of $259 \mathrm{~mm}$ (Fig. 16) compared to the river gauge compared with RMSE $254 \mathrm{~mm}$ on using GNSS ZTD; an improvement of $5 \mathrm{~mm}$. The figure shows anomalies at the peak stage heights on 8 March 2017 and 21 March 2018 with better agreement between altimetry and gauge from June 2017 onwards. Removing the two peak values in March 2017/2018 provided an RMSE of $189 \mathrm{~mm}$ with ECMWF ZTD and $183 \mathrm{~mm}$ with GNSS ZTD. In contrast to Tabatinga, the closer proximity of the gauge at Prieska, gave improved agreement with insitu data and more definitive enhancement on using GNSS ZTD. 


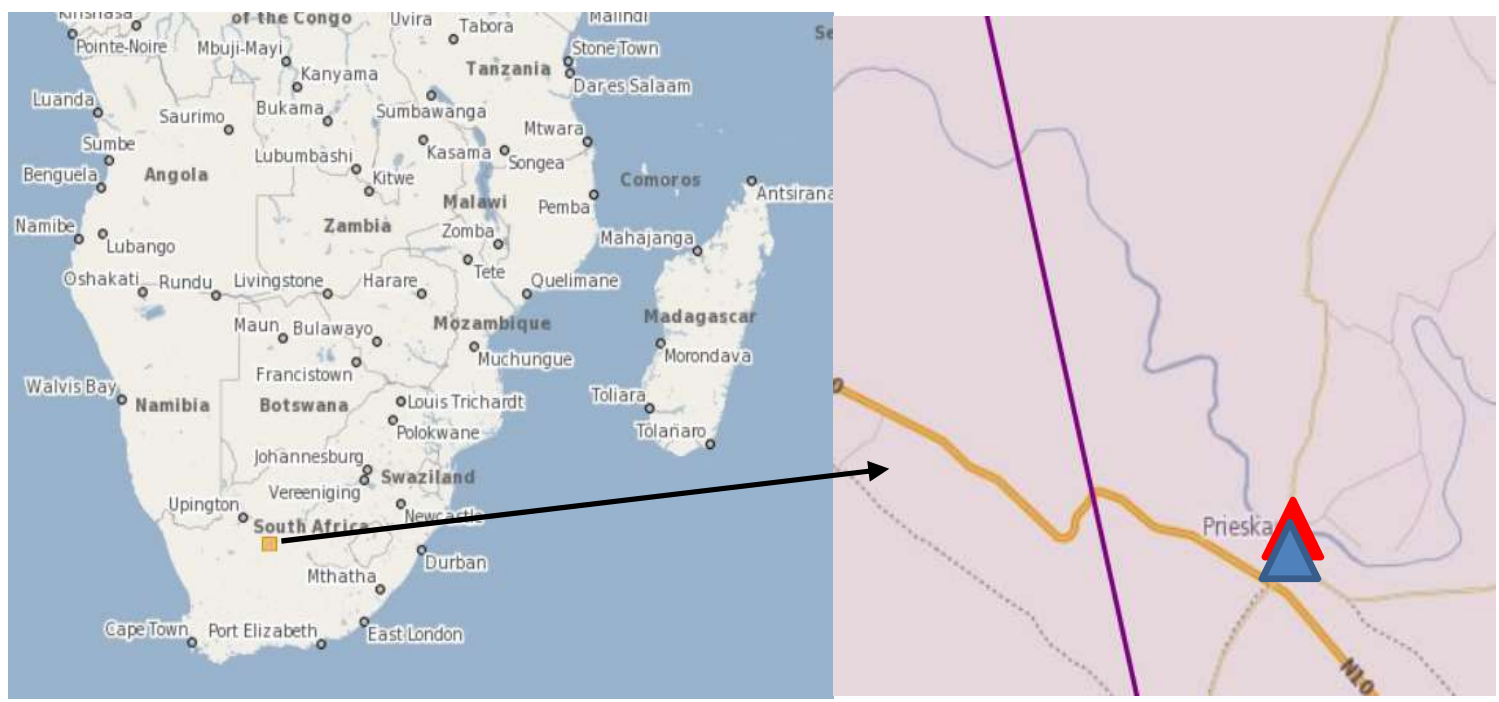

Figure 15 Prieska; Sentinel-3A pass, GNSS receivers and gauge. Symbols as Fig. 13.

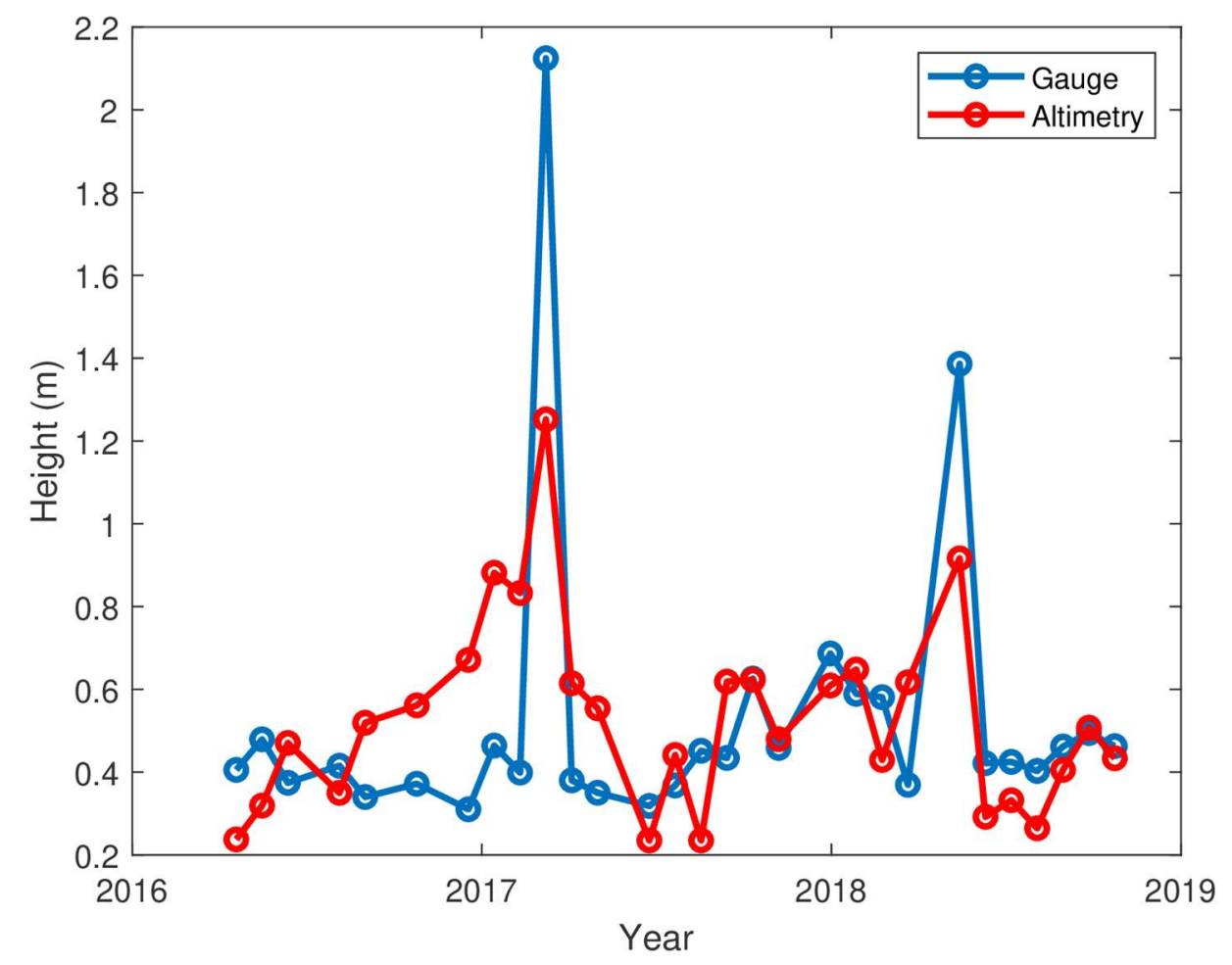

Fig. 16. Prieska Gauge and ECMWF corrected Altimetry comparison

\subsubsection{Rochester, Lake Ontario, North America}

Previous high levels of correlation between altimetric and gauge showed RMS values of $60 \mathrm{~mm}$ (Crétaux, Abarca-del-Río, 2016, Ricko, Carton, 2012). Sentinel-3A pass number 111 crosses the lake $\approx 40$ $\mathrm{km}$ from GNSS station NYPF located outside Rochester (Figure 17). The gauge is $\approx 19 \mathrm{~km}$ from the 
Sentinel-3A ground points and $\approx 22 \mathrm{~km}$ from the GNSS receiver. These data sources provided 33 epochs for comparison between July 2016 and July 2019. Data for the gauge was supplied by National Oceanic and Atmospheric Administration (NOAA). This location provided a more stringent assessment of the GNSS derived ZTD. The RMSE for the 33 Sentinel-3A water heights corrected using ECMWF provided an RMSE of $52.5 \mathrm{~mm}$ compared to the lake gauge (Figure 18), similar to that achieved over a time span of 19 years (Crétaux, Abarca-del-Río, 2016). Replacing ECMWF by GNSS ZTD from NYPF the RMSE reduced to $48.8 \mathrm{~mm}$.

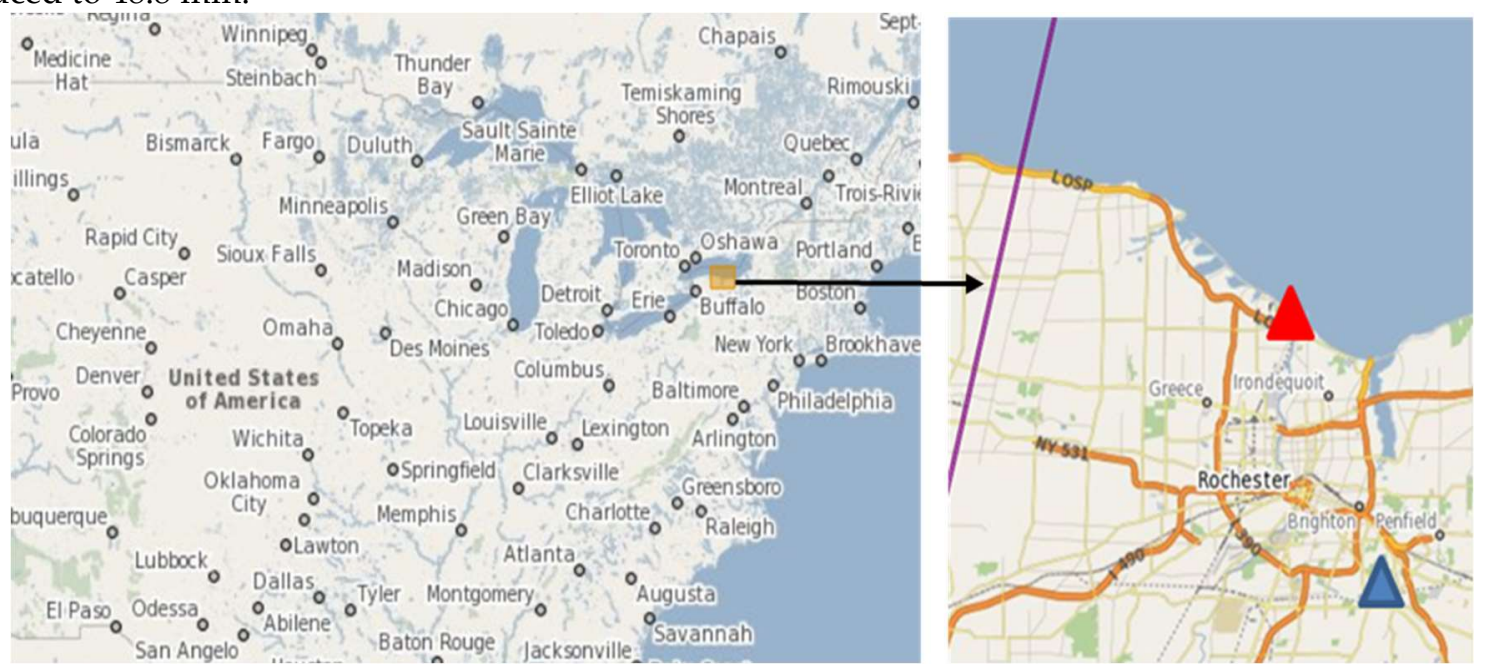

Fig. 17. Rochester; Sentinel-3A pass, GNSS receivers and gauge. Symbols as Fig. 13. 


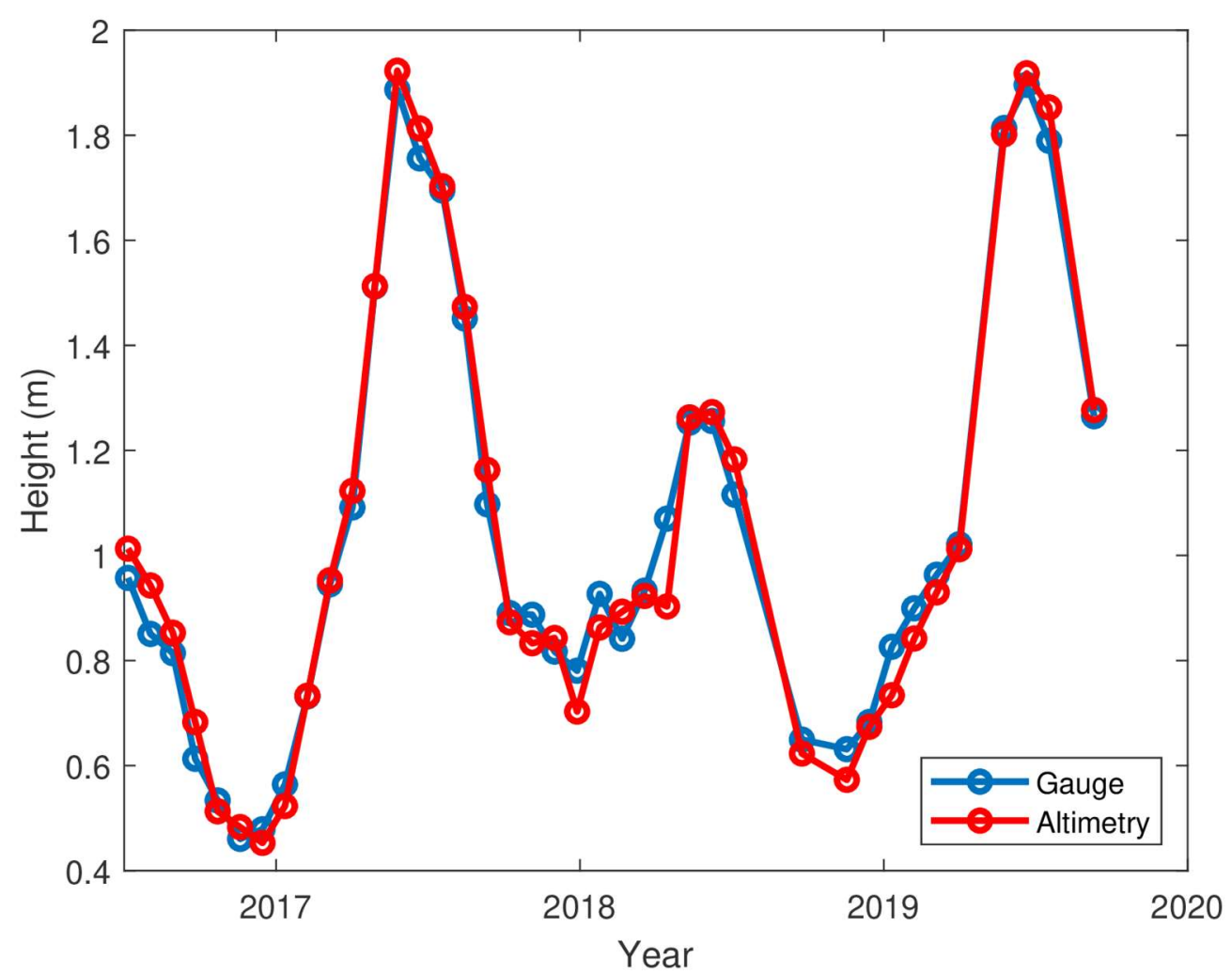

Fig. 18. Ontario Gauge and ECMWF corrected Altimetry comparison

\begin{tabular}{|c|c|c|c|}
\hline & $\begin{array}{c}\text { Tabatinga } \\
\text { Amazon } \\
\text { River }\end{array}$ & $\begin{array}{c}\text { Prieska } \\
\text { Orange } \\
\text { River }\end{array}$ & $\begin{array}{c}\text { Rochester } \\
\text { Lake Ontario }\end{array}$ \\
\hline Sentinel-3A pass - GNSS $(\mathrm{km})$ & 45 & 30 & 40 \\
\hline Sentinel-3A pass - Gauge $(\mathrm{km})$ & 60 & 30 & 19 \\
\hline GNSS - Gauge $(\mathrm{km})$ & 25 & 1 & 22 \\
\hline ZTD ECMWF-GNSS (MAD/ $)(\mathrm{mm})$ & $11.1 / 14.2$ & $5.5 / 12.1$ & $9.4 / 15.8$ \\
\hline Gauge-AlteсмwF $(\mathrm{MAD} / \sigma)(\mathrm{mm})$ & $110 / 412$ & $149 / 263$ & $25.8 / 53.3$ \\
\hline Gauge-AltGNss $(\mathrm{MAD} / \sigma)(\mathrm{mm})$ & $99 / 412$ & $158 / 258$ & $25.0 / 49.5$ \\
\hline Gauge-AlteCMWF (RMSE) (mm) & 404 & 259 & 52.5 \\
\hline Gauge-AltGNsS (RMSE) (mm) & 404 & 254 & 48.8 \\
\hline
\end{tabular}

Table 7 - Gauge comparisons, distances and RMSE Final row quantifies ZTD improvement using GNSS assuming all errors independent

A summary of the results from the three case study sites is presented in Table 7. All validations show that difference between GNSS and ECMWF derived ZTD are at the $5-20 \mathrm{~mm}$ level. Replacing the altimetric ZTD with that from GNSS corresponds to a small improvement of the degree of fit to the gauge data. Results for Lake Ontario show that errors from ECMWF modelled troposphere can contribute around $10 \%$ of the error budget in Sentinel-3A heights. 


\subsection{Catchment Scale Variation}

The preceding validations provide $\mathrm{cm}$ level of confidence on ECMWF ZTD to correct altimetric data over inland waters. More extensive validation requires identification of numerous sites with collocated GNSS, gauge and altimetric passes. As an alternative, the global set of GNSS and ECMWF zenith total delay differences are analysed on a catchment scale to quantify the likely improvement on using GNSS. Catchments for the largest 37 drainage basins were extracted from TRIP (Oki and Sud, 1998) outlines. Data within each basin were used to derive statistical values (Table 8 and Figure 19). A minimum of 150 observations within each basin was required, to prevent outliers skewing the results. Several major basins (e.g. Mekong, Okavango and Kolyma) had little or no observations preventing meaningful analysis.

The majority of the drainage basins have variability as measured by the MAD of less than $10 \mathrm{~mm}$; notable exceptions are the Amazon, Ganges, Indus, Niger, Orinoco, Volta and Zambezi basins in, or near, the tropics. Figure 19 shows box and whisker plots for the drainage basins with the median (red line), upper and lower quartile (blue box), 3 standard deviations from the median (black whiskers) and outliers (red crosses) depicted. Overall, the bias across the drainage basins varies between $-8.2 \mathrm{~mm}$ (Ganges) and $4.5 \mathrm{~mm}$ (AmuDarya).

Figure 19 reveals a large number of outliers that exceed $10 \mathrm{~cm}$. From normal distribution theory the Mean Absolute Deviation (MeAD) is given by

$$
M e A D=\sigma \sqrt{\frac{2}{\pi}}
$$

where $\sigma$ denotes the standard deviation of the normal distribution. Table 13 shows that the Mean Absolute Deviation exceeds the Median Absolute deviation in all catchments indicating the presence of outliers unexpected within a normal distribution. Thus, the differences between ECMWF and GNSS ZTDs are not purely random. The cause is probably multiple including errors due to the height differential correction, sampling of different meteorological conditions due to the distance between GNSS receiver and satellite ground point and to actual differences between GNSS and ECMWF ZTDs. Meteorological change associated with heavy rainfall has been shown (Champollion et al. , 2004) to yield large horizontal gradients but even for the passage of this extreme event the horizontal change over $50 \mathrm{~km}$ is unlikely to account for more than a few $\mathrm{cm}$ in ZTD. The event in Champollion, Masson (2004) yielded a horizontal change of at most $5 \mathrm{~kg} / \mathrm{m}^{2}$ over $50 \mathrm{~km}$. Bevis et al. (1992) give the relationship

$$
Z T D=I W V * Q
$$

where IWV is the Integrated Water Pressure and $Q$ the quotient between ZTD and IWV. Q varies with latitude, season etc. but $\mathrm{Q}=6.5$ or $\mathrm{Q}=6.227$ are typical (Ildikó and Szabolcs, 2018) with error less than 20 $\%$ giving a maximum error of about $3-5 \mathrm{~cm}$. Similarly, (Tahami et al. , 2017) shows a barometric pressure change of $10 \mathrm{mb}$ or less over $50 \mathrm{~km}$ during a hurricane giving a change of $20 \mathrm{~mm}$ or less in ZDD on using Eq. 2. Using these extreme meteorological changes, a total change of about $50-70 \mathrm{~mm}$ is possible over $50 \mathrm{~km}$, although typically much less. Further, corroboration that meteorological change is not the critical factor can be inferred from Figure 7 where outliers are prevalent in differential distances below $20 \mathrm{~km}$. Thus, the outliers in Figure 16 are unlikely the result of horizontal displacement between the altimetric ground point and the GNSS receiver. The inference is that the outliers are either due to a vertical displacement or to a difference between the GNSS and ECMWF ZTD values. A check on the vertical differential height and altitude (c.f. Figures 5 and 6) identified that about $50 \%$ can be attributable to these factors leaving $50 \%$ that are due to differences between GNSS and ECMWF ZTD delays.

Overall, the altimetric community can be reassured that the tropospheric contribution to the error budget for inland water applications is less than $20 \mathrm{~mm}$ at $1 \sigma$ in all major catchments, except possibly the Ganges. Altimetric data assimilation into hydrological models will not be severely impacted at this level of accuracy. 


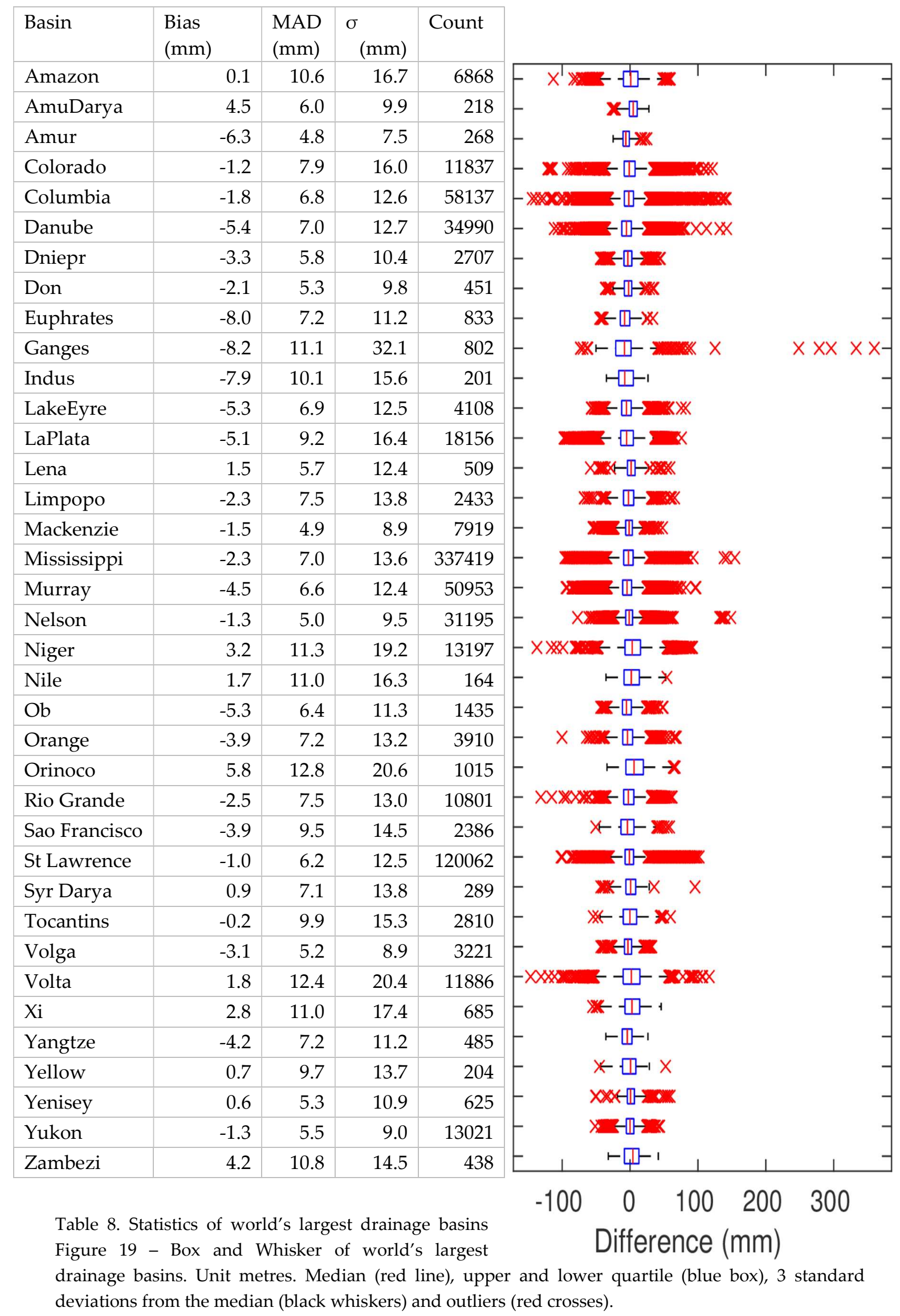

\section{Discussion and Conclusions}


Using a global network of GNSS stations the accuracy of the tropospheric corrections supplied by ECMWF for Sentinel-3A altimetry has been investigated. Globally the MAD of the difference between the GNSS computed total troposphere delay and the ECMWF model is $7.3 \mathrm{~mm}$. Additionally, the ECMWF modelled tropospheric correction has a median $3 \mathrm{~mm}$ greater than the GNSS delay. Within the comparison a number of outliers exceeded $10 \mathrm{~cm}$; potential causes were suggested. In particular, mountainous regions cause the measured altitude and, thus, the dry tropospheric delay to change rapidly. The ECMWF dry tropospheric model is updated once per second and applied to $20 \mathrm{~Hz}$ Sentinel-3A data potentially causing an error through the elevation assumed for each observation. In remote areas such as Antarctica the paucity of meteorological data affects the ECMWF model. In general, small errors within the ECMWF orography cause systematic errors in the modelled tropospheric delay.

The study analysed spatial and temporal signatures of differences between ECMWF and the GIPSY-OASIS computed ZTD. Spatially, the troposphere model was more accurate in polar regions than in tropical regions with a MAD approximately $60 \%$ lower. Temporally, ECMWF model performed worse during warmer summer months than winter. MAD values were up to $65 \%$ larger during the summer months in the $\mathrm{NH}$ and $20 \%$ larger during the $\mathrm{SH}$ summer.

Case studies assessed the enhancement of using GNSS tropospheric values within Sentinel-3A data through correlation with in-situ gauges. Results from two river locations (Amazon and Orange) and from Lake Ontario showed that the RMSE between in situ gauge and altimetry can be reduced when GNSS tropospheric values were used instead of ECMWF modelled values. Residual errors from ECMWF modelled troposphere can contribute around $10 \%$ of the error budget in Sentinel-3A heights of inland waters but usually much less.

Finally, data for 37 of the largest drainage basins was considered. The results showed a small variation from basin to basin but all close to the global average, and typically below $10 \mathrm{~mm}$. ECMWF ZTD measurements differed significantly from the GNSS ZTD. About $50 \%$ of these can be attributed to the data rather than altitude or the vertical and horizontal differential distances between the altimetric ground point and the GNSS receiver location.

Overall, the inland water altimetric community can be reassured that use of ECMWF tropospheric delays contribute less than $20 \mathrm{~mm}$ at $1 \sigma$ in all major catchments, except possibly the Ganges. In particular, the assimilation of altimetric heights as virtual stage data into hydrological models will not be severely impacted at this level of accuracy. However, studies of lake levels as shown for Lake Ontario can benefit from a ZTD correction estimated at a nearby GNSS station.

Acknowledgments: The authors would like to thank ESA and Copernicus for access to the Sentinel-3A data and the European Centre for Medium-Range Weather Forecasts (ECMWF) for the ECMWF model within the Sentinel3A data. Equally we express gratitude to the Nevada Geodetic Lab for GNSS tropospheric values and the following for in situ gauge data: Amazon gauge; Database for Hydrological Time Series of Inland Waters (DAHITI), Orange gauge; Bundesanstalt für Gewässerkunde (BfG) and Lake Ontario; National Oceanic and Atmospheric Administration (NOAA). 


\section{References}

Abdalla, S. Impact of ECMWF Model Change of CY43R3 on STM products. ECMWF, 2017. Arsen, A., Crétaux, J.-F., Abarca del Rio, R. Use of SARAL/AltiKa over mountainous lakes, intercomparison with Envisat mission. Marine Geodesy 38, 534-48, 2015.

DOI: $\underline{10.1080 / 01490419.2014 .1002590}$

Bamber, J.L., Ekholm, S., Krabill, W.B. A new, high-resolution digital elevation model of Greenland fully validated with airborne laser altimeter data. Journal of Geophysical Research: Solid Earth 106, 6733-45, 2001. DOI:10.1029/2000JB900365

Berg, H., Berg, H., Berg, H., Meteorologist, G., Berg, H. Allgemeine Meteorologie: Einführung in die Physik der Atmosphäre. Dümmler, 1948.

Bevis, M., Businger, S., Herring, T.A., Rocken, C., Anthes, R.A., Ware, R.H. GPS meteorology: Remote sensing of atmospheric water vapor using the Global Positioning System. Journal of Geophysical Research: Atmospheres 97, 15787-801, 1992. DOI:10.1029/92JD01517

Biancamaria, S., Lettenmaier, D.P. and Pavelsky, T.M. The SWOT mission and its capabilities for land hydrology. Surveys in Geophysics, 37(2), pp.307-337, 2016. DOI:

Birkett, C.M., Beckley, B. Investigating the performance of the Jason-2/OSTM radar altimeter over lakes and reservoirs. Marine Geodesy 33, 204-38, 2010. DOI: 10.1080/01490419.2010.488983

Birkinshaw, S.J., O'donnell, G., Moore, P., Kilsby, C., Fowler, H., Berry, P. Using satellite altimetry data to augment flow estimation techniques on the Mekong River. Hydrological Processes 24, 3811-25, 2010. DOI:10.1002/hyp.7811

Boehm, J., Werl, B., Schuh, H. Troposphere mapping functions for GPS and very long baseline interferometry from European Centre for Medium-Range Weather Forecasts operational analysis data. Journal of geophysical research: solid earth 111(B02406), 2006. DOI:10.1029/2005]B003629

Champollion, C., Masson, F., Van Baelen, J., Walpersdorf, A., Chéry, J., Doerflinger, E. GPS monitoring of the tropospheric water vapor distribution and variation during the 9 September 2002 torrential precipitation episode in the Cévennes (southern France). Journal of Geophysical Research: Atmospheres 109(D24102), 2004. DOI:10.1029/2004JD004897

Chen, Q., Song, S., Heise, S., Liou, Y.-A., Zhu, W., Zhao, J. Assessment of ZTD derived from ECMWF/NCEP data with GPS ZTD over China. GPS solutions 15, 415-25, 2011. DOI: 10.1007/s10291010-0200-x

Chen, Q.M., Song, S.L. and Zhu, W.Y. 'An analysis for the accuracy of tropospheric zenith delay calculated from ECMWF/NCEP data over Asia', Chinese journal of geophysics, 55(3), pp. 275- 283, 2012. doi:10.1002/cjg2.1722

Crétaux, J.-F., Abarca-del-Río, R., Berge-Nguyen, M., et al. Lake volume monitoring from space. Surveys in Geophysics 37, 269-305, 2016. DOI 10.1007/s10712-016-9362-6

Dando, P. Changes to ECMWF's grids in 2016. 2015.

Davis, J., Herring, T., Shapiro, I., Rogers, A., Elgered, G. Geodesy by radio interferometry: Effects of atmospheric modeling errors on estimates of baseline length. Radio science 20, 1593-607, 1985. DOI:10.1029/RS020i006p01593

Dousa, J., Vaclavovic, P. and Elias, M. Tropospheric products of the second GOP European GNSS reprocessing (1996-2014). Atmospheric Measurement Techniques, 10(9), p.3589, 2017. DOI: 10.5194/amt-10-3589-2017

ECMWF. Part IV:Physical Processes. IFS Documentation CY41R2. ECMWF, 2016.

ECMWF. Changes in ECMWF model. 2019.

Edwards, S., Moore, P. and King, M. Assessment of the Jason-1 and TOPEX/Poseidon microwave radiometer performance using GPS from offshore sites in the north sea. Marine Geodesy, 27(3-4), pp.717-727, 2004. DOI: 10.1080/01490410490883388

Farr, T.G., Kobrick, M. Shuttle Radar Topography Mission produces a wealth of data. Eos, Transactions American Geophysical Union 81, 583-5, 2000. DOI:10.1029/EO081i048p00583 
Fernandes, J., Lázaro, C., Vieira, T., Restano, M., Ambrózio, A., Benveniste, J. Cryosat-2 and Sentinel-3 tropospheric corrections: their evaluation over rivers and lakes. EGU General Assembly Conference Abstracts. pp. 8529, 2017.

Fernandes, M., Lázaro, C. Independent Assessment of Sentinel-3A Wet Tropospheric Correction over the Open and Coastal Ocean. Remote Sensing 10, 484, 2018. DOI: 10.3390/rs10030484

Fernandes, M.J., Lázaro, C., Nunes, A.L. and Scharroo, R. Atmospheric corrections for altimetry studies over inland water. Remote Sensing, 6(6), pp.4952-4997, 2014. DOI: 10.3390/rs6064952

Fletcher, K. Sentinel-3: ESA's global land and ocean mission for GMES operational services. ESA Communications, 2012.

GLOBE, T. Team and others: The Global Land One-kilometer Base Elevation (GLOBE) Digital Elevation Model, Version 1.0. National Oceanic and Atmospheric Administration, National Geophysical Data Center 325, 80305-3328, 1999.

Göttl, F., Dettmering, D., Müller, F., Schwatke, C. Lake level estimation based on CryoSat-2 SAR altimetry and multi-looked waveform classification. Remote Sensing 8, 885, 2016. DOI: $\underline{10.3390 / \mathrm{rs} 8110885}$

Graffigna, V., Hernández-Pajares, M., Gende, M., Azpilicueta, F. and Antico, P. Interpretation of the tropospheric gradients estimated with GPS during Hurricane Harvey. Earth and Space Science, 6(8), pp.1348-1365, 2019. DOI: $10.1029 / 2018 E A 000527$

Haase, J., Ge, M., Vedel, H., Calais, E. Accuracy and variability of GPS tropospheric delay measurements of water vapor in the western Mediterranean. Journal of Applied Meteorology 42, 154768, 2003. DOI: $10.1175 / 1520-0450(2003) 042<1547$ :AAVOGT>2.0.CO;2

Hogg, D.C., Guiraud, F.O. and Decker, M.T. Measurement of excess radio transmission length on earthspace paths. Astronomy and Astrophysics, 95, pp.304-307, 1981.

Hopfield, H.S. Tropospheric effect on electromagnetically measured range: Prediction from surface weather data. Radio Science 6, 357-67, 1971. DOI: 10.1029/RS006i003p00357

Ildikó, J., Szabolcs, R. Developing a global model for the conversion of zenith wet tropospheric delays to integrated water vapour. Acta Geodaetica et Geophysica 53, 259-74, 2018. DOI: $\underline{10.1007 / s 40328-018-}$ $\underline{0215-2}$

Kouba, J. Implementation and testing of the gridded Vienna Mapping Function 1 (VMF1). Journal of Geodesy 82, 193-205, 2008. DOI: 10.1007/s00190-007-0170-0

Lazaro, C., Fernandes, J., Vieira, T. and Vieira, E. A coastally improved global dataset of wet tropospheric corrections for satellite altimetry. Earth System Science Data, 2019. DOI: 10.5194/essd2019-171

Legeais, J.F., Ablain, M. and Thao, S. Evaluation of wet troposphere path delays from atmospheric reanalyses and radiometers and their impact on the altimeter sea level. Ocean Science, 10(6), p.893, 2014. DOI: 10.5194/os-10-893-2014

Liu, H., Jezek, K., Li, B., Zhao, Z. Radarsat Antarctic Mapping Project digital elevation model version 2. Radarsat Antarctic Mapping Project digital elevation model version 2, Boulder, Colorado USA: National Snow and Ice Data Center. Digital media., 2001.

Michailovsky, C.I., Milzow, C. and Bauer-Gottwein, P. Assimilation of radar altimetry to a routing model of the Brahmaputra River. Water Resources Research, 49(8), pp.4807-4816, 2013. DOI: $\underline{10.1002 / \text { wrcr. } 20345}$

Moore, P., Birkinshaw, S., Ambrózio, A., Restano, M., Benveniste, J. CryoSat-2 Full Bit Rate Level 1A processing and validation for inland water applications. Advances in Space Research 62, 1497-515, 2018. DOI: $\underline{10.1016 / j . a s r .2017 .12 .015}$

Mostafavi, M., Sh, R., Emadi, R., Azad, T. River Monitoring Over Amazon and Danube Basin Using Multi-Mission Satellite Radar Altimetry. J Hydrogeol Hydrol Eng 7: 2. of 10, 12-4, 2018. DOI: 10.4172/2325-9647.1000166

Murray, K.D., Bekaert, D.P. and Lohman, R.B. Tropospheric corrections for InSAR: statistical assessments and applications to the Central United States and Mexico. Remote Sensing of Environment, 232, p.111326, 2019. DOI: 10.1016/j.rse.2019.111326 
Niell, A. Global mapping functions for the atmosphere delay at radio wavelengths. Journal of Geophysical Research: Solid Earth 101, 3227-46, 1996. DOI: 10.1029/95]B03048

Oki, T., Sud, Y. Design of Total Runoff Integrating Pathways (TRIP) - A global river channel network. Earth interactions 2, 1-37, 1998. DOI: 10.1175/1087-3562(1998)002<0001:DOTRIP>2.3.CO;2

Pan, L., Guo, F. Real-time tropospheric delay retrieval with GPS, GLONASS, Galileo and BDS data. Sci. Rep. 8, 17067, 2018. DOI: 10.1038/s41598-018-35155-3

de Paiva, R.C.D., Buarque, D.C., Collischonn, W., Bonnet, M.P., Frappart, F., Calmant, S. and Bulhões Mendes, C.A. Large-scale hydrologic and hydrodynamic modeling of the Amazon River basin. Water Resources Research, 49(3), pp.1226-1243, 2013. DOI: 10.1002/wrcr.20067

Parracho, A.C., Bock, O. and Bastin, S. Global IWV trends and variability in atmospheric reanalyses and GPS observations, 2018. DOI: 10.5194/acp-18-16213-2018

Ricko, M., Carton, J.A., Birkett, C.M., Crétaux, J.-F. Intercomparison and validation of continental water level products derived from satellite radar altimetry. Journal of Applied Remote Sensing 6, 061710, 2012. DOI: $\underline{10.1117 / 1 . J R S .6 .061710}$

Rodriguez, E., Morris, C.S., Belz, J.E., Chapin, E.C., Martin, J.M., Daffer, W. and Hensley, S. An assessment of the SRTM topographic products, 2005.

Saastamoinen, J. Atmospheric correction for the troposphere and stratosphere in radio ranging satellites. The use of artificial satellites for geodesy 15, 247-51, 1972. DOI: $\underline{10.1029 / G M 015 p 0247}$

Schneider, R., Godiksen, P.N., Villadsen, H., Madsen, H. and Bauer-Gottwein, P. Application of CryoSat-2 altimetry data for river analysis and modelling. Hydrology and Earth System Sciences, 21, pp.751-764, 2017. DOI: 10.5194/hess-21-751-2017

Song, C., Ye, Q., Sheng, Y., Gong, T. Combined ICESat and CryoSat-2 altimetry for accessing water level dynamics of Tibetan lakes over 2003-2014. Water 7, 4685-700, 2015. DOI: 10.3390/w7094685

Tahami, H., Park, J., Choi, Y. The Preliminary Study on the Prediction of a Hurricane Path by GNSS Derived PWV Analysis. Proceedings of the ION 2017 Pacific PNT Meeting, Honolulu, Hawaii. 2017. DOI: $\underline{10.33012 / 2017.15074}$

Teke, K., Böhm, J., Nilsson, T., Schuh, H., Steigenberger, P., Dach, R., Heinkelmann, R., Willis, P., Haas, R., García-Espada, S. and Hobiger, T. Multi-technique comparison of troposphere zenith delays and gradients during CONT08. Journal of Geodesy, 85(7), p.395, 2011. DOI: 10.1007/s00190-010-0434-y

Teke, K., Nilsson, T., Böhm, J., Hobiger, T., Steigenberger, P., García-Espada, S., Haas, R. and Willis, P. Troposphere delays from space geodetic techniques, water vapor radiometers, and numerical weather models over a series of continuous VLBI campaigns. Journal of Geodesy, 87(10-12), pp.981-1001, 2013. DOI: $10.1007 / \mathrm{s} 00190-013-0662-\mathrm{z}$

Tourian, M., Tarpanelli, A., Elmi, O., et al. Spatiotemporal densification of river water level time series by multimission satellite altimetry. Water Resources Research 52, 1140-59, 2016. DOI: 10.1002/2015WR017654

Vey, S., Dietrich, R., Rülke, A., Fritsche, M., Steigenberger, P. and Rothacher, M. Validation of precipitable water vapor within the NCEP/DOE reanalysis using global GPS observations from one decade. Journal of Climate, 23(7), pp.1675-1695, 2010. DOI: 10.1175/2009JCLI2787.1

Vieira, T., Fernandes, M.J., Lázaro, C. Independent assessment of on-board microwave radiometer measurements in coastal zones using tropospheric delays from gnss. IEEE Transactions on Geoscience and Remote Sensing 57, 1804-16, 2018. DOI: 10.1109/TGRS.2018.2869258

Wells, D.E., N. Beck, D. Delikaraoglou, A. Kleusberg, E.J. Krakiwsky, G. Lachapelle, R.B. Langley, M. Nakiboglu, K.P. Schwarz, J.M. Tranquilla and P. Vanicek. Guide to GPS positioning. Fredericton, New Brunswick : Canadian GPS Associates, Fredericton, New Brunswick, 1986.

Zakharova, E., Nielsen, K., Kamenev, G. and Kouraev, A. River discharge estimation from radar altimetry: Assessment of satellite performance, river scales and methods. Journal of Hydrology, 583, p.124561, 2020. DOI: $10.1016 /$ j.jhydrol.2020.124561 
